\title{
Different Effects of Two ENSO Types on Arctic Surface Temperature in Boreal Winter
}

\author{
ZHIYU LI AND WENJUN ZHANG \\ CIC-FEMD/ILCEC, Key Laboratory of Meteorological Disaster of Ministry of Education, and College of Atmospheric Sciences, \\ Nanjing University of Information Science and Technology, Nanjing, China \\ MALTE F. STUECKER \\ Center for Climate Physics, Institute for Basic Science, and Pusan National University, Busan, South Korea
}

\section{HAIMING XU}

CIC-FEMD/ILCEC, Key Laboratory of Meteorological Disaster of Ministry of Education, and College of Atmospheric Sciences, Nanjing University of Information Science and Technology, Nanjing, China

\section{FEI-FEI JIN}

Department of Atmospheric Sciences, School of Ocean and Earth Science and Technology, University of Hawai'i at Mānoa, Honolulu, Hawaii

\section{CHAO LIU}

\begin{abstract}
CIC-FEMD/ILCEC, Key Laboratory of Meteorological Disaster of Ministry of Education, and College of Atmospheric Sciences, Nanjing University of Information Science and Technology, Nanjing, China
\end{abstract}

(Manuscript received 7 November 2018, in final form 6 May 2019)

\begin{abstract}
The present work investigates different responses of Arctic surface air temperature (SAT) to two ENSO types based on reanalysis datasets and model experiments. We find that eastern Pacific (EP) ENSO events are accompanied by statistically significant SAT responses over the Barents-Kara Seas in February, while central Pacific (CP) events coincide with statistically significant SAT responses over northeastern Canada and Greenland. These impacts are largely of opposite sign for ENSO warm and cold phases. During EP El Niño in February, the enhanced tropospheric polar vortex over Eurasia and associated local low-level northeasterly anomalies over the Barents-Kara Seas lead to anomalously cold SAT in this region. Simultaneously, the enhanced tropospheric polar vortex leads to enhanced sinking air motion and consequently reduced cloud cover. This in turn reduces downward infrared radiation (IR), which further reduces SAT in the Barents-Kara Seas region. Such a robust response cannot be detected during other winter months for EP ENSO events. During CP El Niño, the February SATs over northeastern Canada and Greenland are anomalously warm and coincide with a weakened tropospheric polar vortex and related local low-level southwesterly anomalies originating from the Atlantic Ocean. The anomalous warmth can be enhanced by the local positive feedback. Similar SAT signals as in February during CP ENSO events can also be seen in January, but they are less statistically robust. We demonstrate that these contrasting Arctic February SAT responses are consistent with responses to the two ENSO types with a series of atmospheric general circulation model experiments. These results have implications for the seasonal predictability of regional Arctic SAT anomalies.
\end{abstract}

\section{Introduction}

The Arctic has received extensive attention in the climate community because of its significance to weather and climate in the mid-high latitudes (e.g.,

Corresponding author: Wenjun Zhang, zhangwj@nuist.edu.cn
Screen and Simmonds 2010; Francis and Vavrus 2012, 2015; Cohen et al. 2014; Cohen 2016; Cohen et al. 2018; Overland and Wang 2010; Overland et al. 2011, 2016; $\mathrm{Wu}$ 2017; Coumou et al. 2018). Importantly, in response to greenhouse gas forcing, Arctic temperatures are warming much faster than the rest of the world (e.g., Holland and Bitz 2003; Screen and Simmonds 2010; 
Serreze and Barry 2011; Stuecker et al. 2018), a phenomenon known as Arctic amplification. The Arctic warming signal varies with season and by location, with the maximum warming occurring during boreal winter (Serreze and Francis 2006; Serreze and Barry 2011; Ding et al. 2014; Gong et al. 2017; Stuecker et al. 2018) and being mostly located in northeastern Canada and Greenland as well as the Barents-Kara Seas (Screen and Simmonds 2010; Ding et al. 2014; Khan et al. 2014; Jung et al. 2017). Many possible mechanisms are proposed for explaining recent Arctic warming, such as ice-albedo feedback (Budyko 1969; Sellers 1969; Stroeve et al. 2012; Serreze and Barry 2011), poleward heat and moisture fluxes from extrapolar regions (Cai 2005, 2006; Graversen 2006; Lu and Cai 2010; Lee et al. 2011a; Lee 2014; Ding et al. 2014; Krishnamurti et al. 2015), and water vapor and cloud feedbacks (Francis and Hunter 2006; Screen and Simmonds 2010; Serreze et al. 2012; Ghatak and Miller 2013). Tropical Pacific sea surface temperature (SST) changes-that are likely a combination of a forced signal and internal variability-are also argued to have some contribution on the recent warming trend over some Arctic regions (Ding et al. 2014; Svendsen et al. 2018). Recent studies demonstrated that the dominant process for the amplification of Arctic warming (compared to the tropics) in response to $\mathrm{CO}_{2}$ forcing is the local lapse rate feedback, with albedo feedback and the curvature of the Planck feedback playing secondary roles (Pithan and Mauritsen 2014; Stuecker et al. 2018).

Arctic warming may also influence the midlatitude atmospheric circulation and regional climate through a modulation of the meridional thermal gradient in the atmosphere (Cohen et al. 2014; Kug et al. 2015; Wu 2017); however, the importance and robustness of this linkage is still strongly debated (e.g., Barnes 2013; Screen and Simmonds 2013; Barnes and Screen 2015). It is noteworthy that warming in different Arctic regions may lead to different remote climate anomaly patterns. For example, surface air temperature (SAT) warming over the Barents-Kara Seas is argued to favor more frequent cold surges across East Asia (Honda et al. 2009; Inoue et al. 2012; Tang et al. 2013; Kug et al. 2015), whereas SAT warming over the East Siberian and Chukchi Seas may be associated with extreme cold winters in North America (e.g., Kug et al. 2015).

Superimposed on a long-term warming trend, Arctic SAT exhibits interannual fluctuations that remain poorly understood. Part of this is likely internal variability of the coupled Arctic air-sea ice system, but part might be explained by teleconnections from the most important coupled air-sea interaction phenomenon, El Niño-Southern Oscillation (ENSO; e.g., Lee 2012; Hu et al. 2016a), which is the dominant source of global interannual climate variability (e.g., Bjerknes 1969; Wyrtki 1975; Schopf and Suarez 1988; Jin 1997; Neelin et al. 1998; Wallace et al. 1998; Timmermann et al. 2018). ENSO-associated tropical SST anomalies may induce Arctic SAT anomalies by exciting poleward-propagating atmospheric Rossby waves (Sassi et al. 2004; Lee 2012; $\mathrm{Hu}$ et al. 2016a). For instance, it was shown that El Niño usually coincides with anomalous cooling over the East Siberian Sea while La Niña often coincides with anomalous warming of the Kara Sea during boreal winter (Lee 2012). This linkage between ENSO and Arctic SAT on interannual time scales could be of importance for seasonal-to-interannual prediction of Arctic SAT.

However, ENSO events exhibit considerable diversity in their frequency, location, intensity, and meridional scale (An and Wang 2000; Ashok et al. 2007; Yeh et al. 2009; Zhang et al. 2009, 2013; Timmermann et al. 2018). One of the latest major advances in ENSO research is the discovery of a new El Niño type. Its air-sea action center is located over the central Pacific (CP), which is different from the traditional El Niño with maximum SST anomalies located in the eastern Pacific (EP) (Larkin and Harrison 2005; Ashok et al. 2007; Weng et al. 2007; Kao and Yu 2009; Kug et al. 2009; Ren and Jin 2011). Similarly, La Niña events can be separated into two types according to the zonal location of their SST anomalies (Shinoda et al. 2011; Zhang et al. 2015, 2019). Importantly, these two different ENSO types exhibit very different climate impacts, especially in East Asia and western Europe (e.g., Weng et al. 2007; Cai and Cowan 2009; Feng et al. 2010; Feng and Li 2013; Zhang et al. 2011, 2013, 2014, 2015, 2019; Yu et al. 2012; Tedeschi et al. 2013). A recent study has shown that statistically significant Arctic climate responses to CP ENSO were observed at high latitudes during boreal summer $(\mathrm{Hu}$ et al. 2016a). We hypothesize that the observed ENSO diversity might complicate ENSO's statistical relationship with Arctic SAT anomalies during boreal winter.

At present, there are few studies on the relationship between ENSO and Arctic SAT from the perspective of ENSO diversity (Johnson and Kosaka 2016). One fundamental scientific question that deserves attention is whether the distinct Arctic impacts from different flavors of ENSO can be identified from the short observational data. Our present study investigates the different impacts of the two ENSO types on regional Arctic SAT anomalies based on observations and model experiments, and possible dynamical mechanisms for the linkage are discussed. We are focusing on the boreal winter season given the importance of winter Arctic SAT and the fact that ENSO peaks during this season. In the remainder of the paper, section 2 introduces data, 
methods, definition of ENSO events, and our experimental design. Section 3 reports different Arctic SAT responses to EP and CP ENSO events, respectively. Associated mechanisms are discussed through observational analyses and a series of general circulation model experiments in section 4. The major conclusions are summarized and discussed in section 5 .

\section{Data and methodology}

\section{a. Data and methodology}

Monthly and daily air temperatures at $2 \mathrm{~m}$, monthly cloud cover, radiation, and variables characterizing the atmospheric circulation were obtained from the National Centers for Environmental PredictionNational Center for Atmospheric Research (NCEPNCAR) Reanalysis-1 data (Kalnay et al. 1996). ENSO-associated SST anomalies were examined based on the Hadley Centre Sea Ice and SST dataset (HadISST), version 1.1 (Rayner et al. 2003). Precipitation data were utilized from the precipitation reconstruction (PREC; Chen et al. 2002), provided by the National Oceanic and Atmospheric Administration (NOAA). We also utilized air temperatures at $2 \mathrm{~m}$ from the $40-\mathrm{yr}$ European Centre for Medium-Range Weather Forecasts (ECMWF) Re-Analysis (ERA-40; Uppala et al. 2005) and the Japanese 55-year Reanalysis (JRA-55), provided by the Japan Meteorological Agency (JMA; Ebita et al. 2011). Our analyses focus on the period of 1960-2017 and anomalies for all variables were calculated as the deviations from the climatological mean over this period. To focus on the interannual variability, each dataset was first linearly detrended and then a 10-yr high-pass Lanczos filter was applied (Duchon 1979). The first and last 5 years of the datasets were then removed prior to the analysis to avoid possible boundary distortion associated with the filtering process. The qualitative conclusions remain the same even if the high-pass filtering is not conducted (not shown). Although the ENSO peak time occurs during boreal winter [December-February (DJF)], the most significant influences of ENSO on highlatitude climate are usually found in late winter (e.g., Moron and Gouirand 2003; Zhang et al. 2015, 2019). Therefore, we investigate the impacts during January and February of the ENSO decaying year in this study. Linear correlation and composite analyses were used to investigate the relationship between the ENSO and Arctic SAT. Bootstrapping was used throughout the manuscript to determine statistical significance. A false discovery rate (FDR) test has also been used to deal with the multiplicity problem in our study (Wilks 2016). The linear ENSO response here is defined as the difference between $\mathrm{El}$ Niño and La Niña events.
TABLE 1. Two types of ENSO events during 1965-2012.

\begin{tabular}{ccc}
\hline \hline & Eastern Pacific (EP) type & Central Pacific (CP) type \\
\hline El Niño & $1965 / 66,1969 / 70,1972 / 73$, & $1968 / 69,1977 / 78,1979 / 80$, \\
& $1976 / 77,1982 / 83,1986 / 87$, & $1994 / 95,2002 / 03,2004 / 05$, \\
La Niña & $1991 / 92,1997 / 98$ & $2006 / 07,2009 / 10$ \\
& $1964 / 65,1970 / 71,1984 / 85$, & $1973 / 74,1975 / 76,1983 / 84$, \\
& $2005 / 06,2007 / 08$ & $1988 / 89,2008 / 09,2010 / 11$, \\
\hline
\end{tabular}

\section{b. Definition of ENSO events}

Various ENSO indices have been proposed to separate El Niño events into two types (Ashok et al. 2007; Kao and Yu 2009; Ren and Jin 2011; Hu et al. 2016b); however, these indices are not able to distinguish different La Niña types well (Zhang et al. 2015, 2019). Here, we first select ENSO winters on the basis of the Climate Prediction Center (CPC) definition (a threshold of $\pm 0.5^{\circ} \mathrm{C}$ of the 3-month running mean of Niño-3.4 SST anomalies for five consecutive overlapping seasons). Then, different ENSO types (Table 1) are identified based on their spatial distribution of SST anomalies, following a previous definition (Zhang et al. 2011, 2013, 2014, 2015, 2019). The EP ENSO events are defined when the SST anomaly center is located east of $150^{\circ} \mathrm{W}$ during boreal winter, whereas CP ENSO events are defined when the SST anomaly center is located west of this longitude. We select the longitude of $150^{\circ} \mathrm{W}$ because it is the boundary of the Niño- $3\left(5^{\circ} \mathrm{S}-5^{\circ} \mathrm{N}, 150^{\circ}-90^{\circ} \mathrm{W}\right)$ and Niño- $4\left(5^{\circ} \mathrm{S}-5^{\circ} \mathrm{N}, 160^{\circ} \mathrm{E}-150^{\circ} \mathrm{W}\right)$ regions, which are usually used to define EP and CP ENSO events (e.g., Kim et al. 2009; Kug et al. 2009). This method can effectively distinguish between two ENSO types for both El Niño and La Niña events. Different definitions of EP and CP ENSO are also examined (Kug et al. 2009; Yu et al. 2012; Yu and Kim 2013). Despite some slight differences, the SAT responses in the key regions discussed in our studies are consistent for these definitions (not shown). Thus, it seems that our conclusions are insensitive to the way in which ENSO events are partitioned. For consecutive ENSO years, the relatively stronger El Niño and La Niña winters are taken as a representative, such as 1986/87 for the 1986/87/88 El Niño event, and 1970/71 for the 1970/71/72 La Niña event. If we include the relatively weak winters in our analysis, the qualitative conclusions remain the same with only small differences evident (not shown).

\section{c. Experimental design}

All model experiments are conducted using the Geophysical Fluid Dynamics Laboratory (GFDL) global Atmospheric Model, version 2.1 (AM2.1; Anderson et al. 2004), at a horizontal resolution of $2.5^{\circ}$ longitude $\times 2^{\circ}$ 
TABLE 2. List of the conducted SST perturbation experiments.

\begin{tabular}{lc}
\hline \hline Experiment & \multicolumn{1}{c}{ Description of the SST perturbation } \\
\hline EPW & $\begin{array}{r}\text { Warm EP El Niño-related SST anomalies are } \\
\text { imposed in the tropical Pacific }\left(30^{\circ} \mathrm{S}-30^{\circ} \mathrm{N},\right.\end{array}$ \\
& $\left.120^{\circ} \mathrm{E}-90^{\circ} \mathrm{W}\right)$ \\
CPW & As in EPW, but for the CP El Niño events \\
EPC & Cold EP La Niña-related SST anomalies are \\
& imposed in the tropical Pacific $\left(30^{\circ} \mathrm{S}-30^{\circ} \mathrm{N}\right.$, \\
& $\left.120^{\circ} \mathrm{E}-90^{\circ} \mathrm{W}\right)$ \\
CPC & $\mathrm{As}$ in EPC, but for the CP La Niña events
\end{tabular}

latitude. The climatological SST and sea ice concentrations with their seasonal variations were used as boundary conditions to obtain the climatological reference state. Four sensitivity experiments [denoted warm EP (EPW), warm CP (CPW), cold EP (EPC), and cold $\mathrm{CP}$ (CPC)] were conducted (Table 2). In the EPW simulation, the winter SST anomalies obtained from the composite of EP El Niño events were imposed on the monthly climatological SST over the tropical Pacific $\left(30^{\circ} \mathrm{S}-30^{\circ} \mathrm{N}, 120^{\circ} \mathrm{E}-90^{\circ} \mathrm{W}\right)$ from October to February. SST anomalies outside of the region were set to zero to focus on the role of tropical Pacific SST anomalies. Importantly, SST anomalies outside of the tropical Pacific also play some role in ENSO-induced climate impacts (e.g., Zhang et al. 2016; Stuecker et al. 2017), which we do not explore further in this paper. Similarly, the other three experiments (CPW, EPC, and CPC; listed in Table 2) were conducted by imposing their corresponding SST anomaly patterns, respectively. Each simulation was integrated for 20 years and the output from the last 10 years of the integration was averaged to significantly reduce the internal unforced variability. We also examine possible influences of integration time by conducting another integration for 35 years. The results remain the qualitatively similar despite some slight differences (not shown), suggesting that the analysis conclusions are not sensitive to the integration time.

\section{Different Arctic SAT responses to two types of ENSO}

Figure 1 displays the SST, near-surface $(10 \mathrm{~m})$ wind, and precipitation anomalies associated with the two ENSO types in the tropical Pacific Ocean. The linear composite (El Niño minus La Niña) is shown here. As pointed out in previous studies (e.g., Zhang et al. 2019), the zonal locations of the air-sea action centers are distinct for these two ENSO types. The SST anomaly center of the EP ENSO is located in the eastern Pacific, accompanied with convergence of anomalous zonal wind there, while those of the CP ENSO are in the central Pacific. Correspondingly, the precipitation anomalies during EP ENSO winter extend from the date line to the eastern equatorial Pacific and those during CP ENSO winter are confined to the central Pacific. The distinct diabatic heating anomalies associated with the two ENSO types may lead to different extratropical teleconnections to the Arctic.

We next examine the January and February 2-m air temperature anomalies over the Arctic for the two ENSO types, respectively. As shown in Fig. 2a, almost no statistically significant signals are found over the Arctic during EP ENSO January. The only significant warm anomalies are located over northwestern North America, a pattern that is associated with the PacificNorth America (PNA) teleconnection (Papineau 2001; (a) EP_ENSO

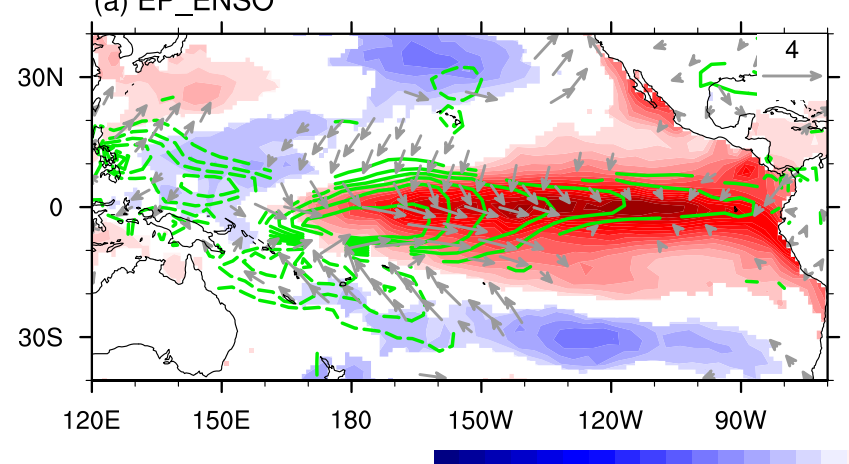

(b) CP_ENSO

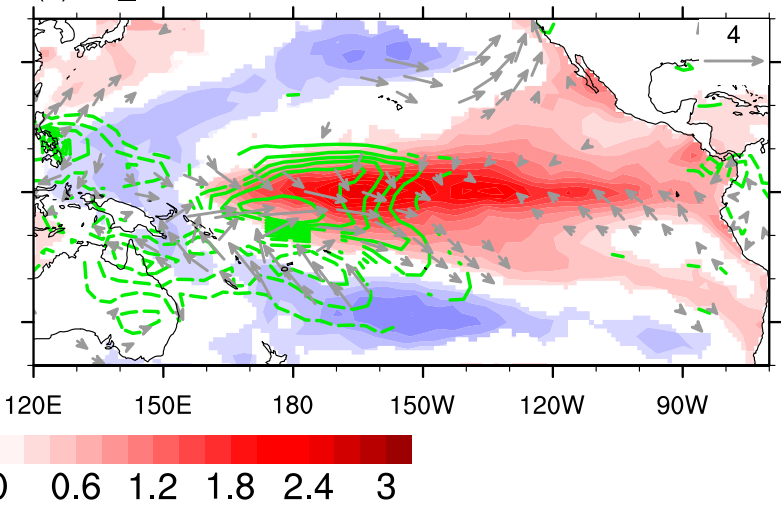

FIG. 1. Composites of winter mean (DJF) SST (shading; ${ }^{\circ} \mathrm{C}$ ), $10-\mathrm{m}$ wind (vectors; $\mathrm{m} \mathrm{s}^{-1}$ ), and precipitation anomalies (contours from -6 to 6 in increments of 1 with negative values dashed; $\mathrm{mm} \mathrm{day}^{-1}$ ) over the tropical Pacific during (a) EP ENSO (EP El Niño minus EP La Niña), and (b) CP ENSO (CP El Niño minus CP La Niña) events. Areas for which the SST and precipitation anomaly composites exceed the $90 \%$ confidence level are shown. The $10-\mathrm{m}$ wind anomalies are shown only when either the anomalous zonal or meridional wind is statistically significant at the $90 \%$ confidence level. 
(a) EP_ENSO (Jan)

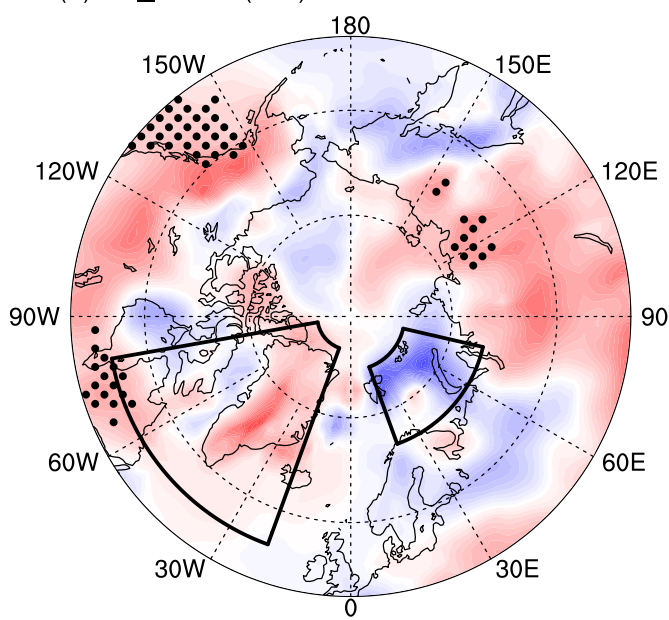

(c) EP_ENSO (Feb)

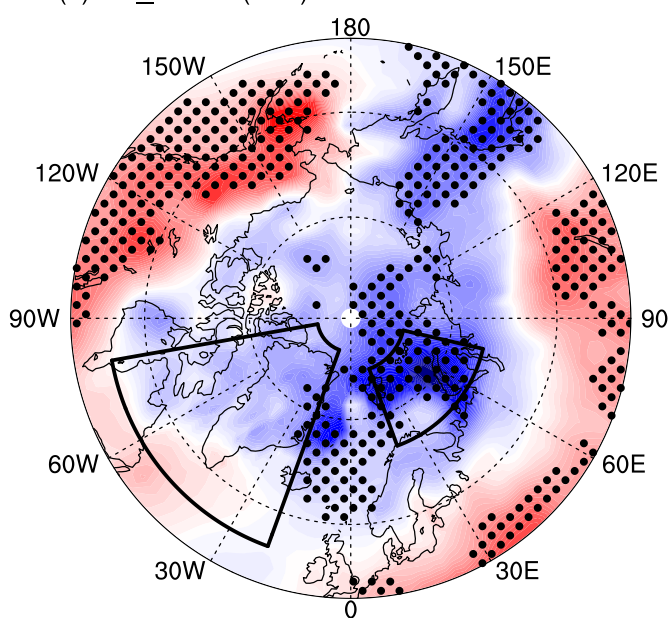

(b) CP ENSO (Jan)

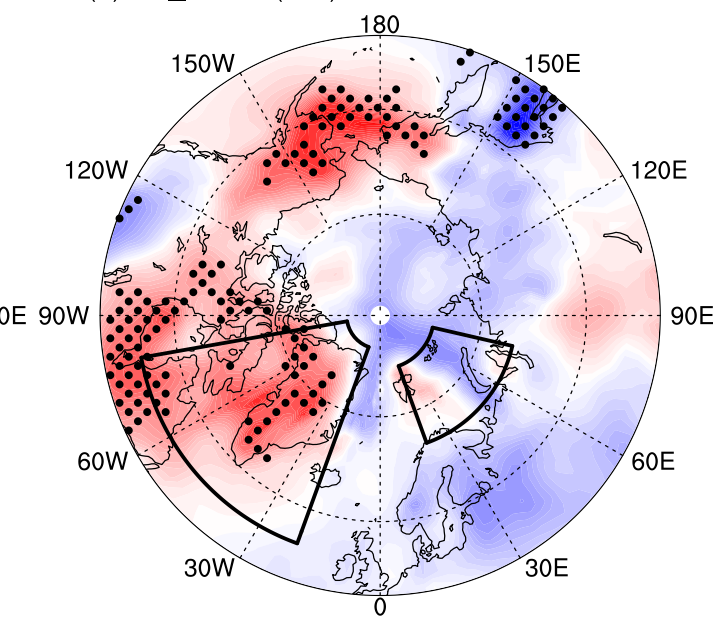

(d) CP_ENSO (Feb)
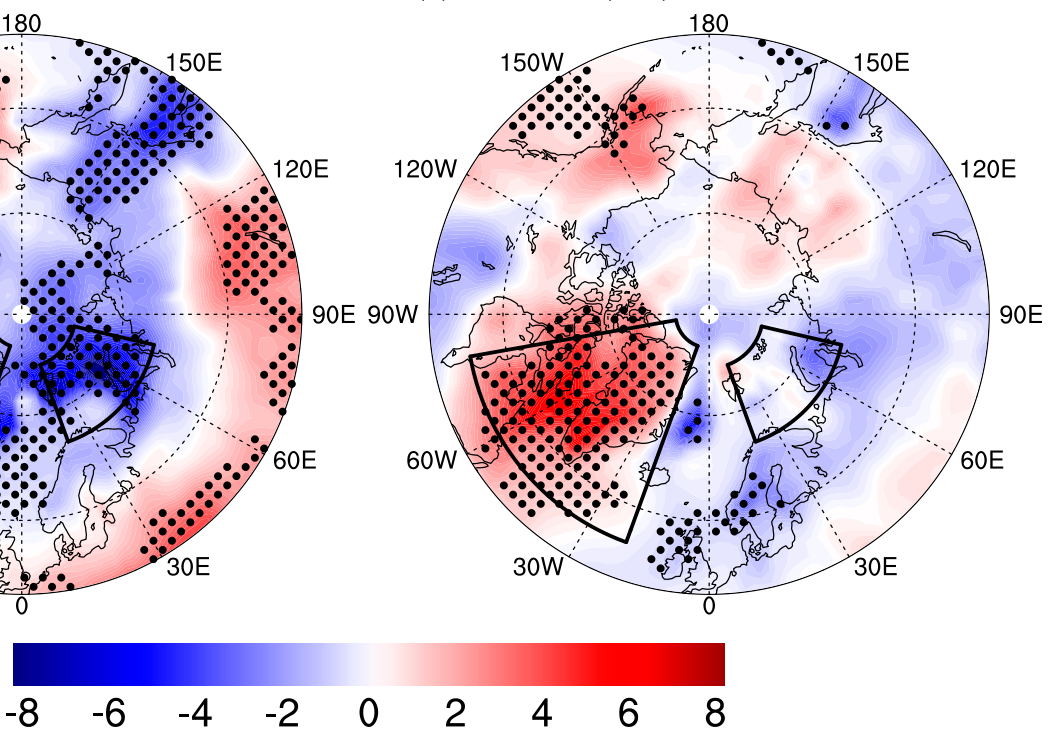

FIG. 2. Composites of 2-m temperature anomalies (shading; ${ }^{\circ} \mathrm{C}$ ) for (left) EP ENSO (EP El Niño minus EP La Niña), and (right) CP ENSO (CP El Niño minus CP La Niña) events during (a),(b) January and (c),(d) February. Stippling indicates that the composites are statistically significant at the $90 \%$ confidence level. Black boxes outline the Barents-Kara Seas $\left(20^{\circ}-77^{\circ} \mathrm{E}, 70^{\circ}-82^{\circ} \mathrm{N}\right)$ and northeastern Canada and Greenland $\left(80^{\circ}-20^{\circ} \mathrm{W}, 55^{\circ}-85^{\circ} \mathrm{N}\right)$ regions, respectively.

Deng et al. 2012). During CP ENSO January, a statistically significant anomalous cooling is found in the Okhotsk Sea and a pronounced warming in northeastern Canada and Greenland, in addition to the response related to the PNA teleconnection. In comparison, the Arctic SAT response to CP ENSO is relatively similar to the EP ENSO pattern during January (with a spatial correlation of 0.47 over the area north of $50^{\circ} \mathrm{N}$ ) (Fig. 2b). In contrast, the SAT anomaly patterns for EP ENSO and CP ENSO differ substantially during February (with a spatial correlation of 0.30). In particular, the warming over northwestern North America is strongly enhanced and expanded in the former. Simultaneously, a belt of significant cold anomalies stretches eastward from the Norway Sea to the Okhotsk Sea with its center located in the BarentsKara Seas region. A belt of warm anomalies is evident along the midlatitudes $\left(\sim 50^{\circ} \mathrm{N}\right)$ in Eurasia (Fig. $\left.2 \mathrm{c}\right)$. In contrast to the EP ENSO response, the SAT anomalies during CP ENSO are similar in January and February. In the latter, the cold anomalies over the Okhotsk Sea are not statistically significant, whereas the warm anomalies over northeastern Canada and Greenland are enhanced (Fig. 2d). Similar results can be derived based on other reanalysis data, such as the ERA-40 and JRA-55 datasets. 
(a) EP El Nino

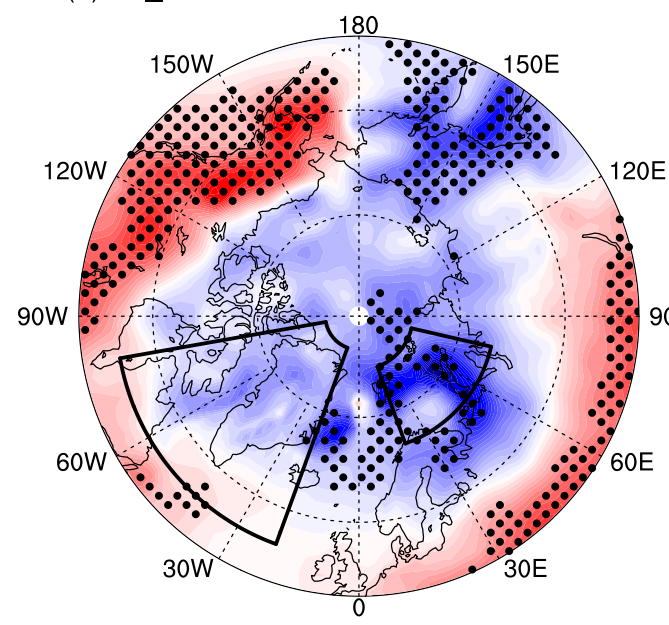

(c) $\mathrm{CP}_{-}$El Nino

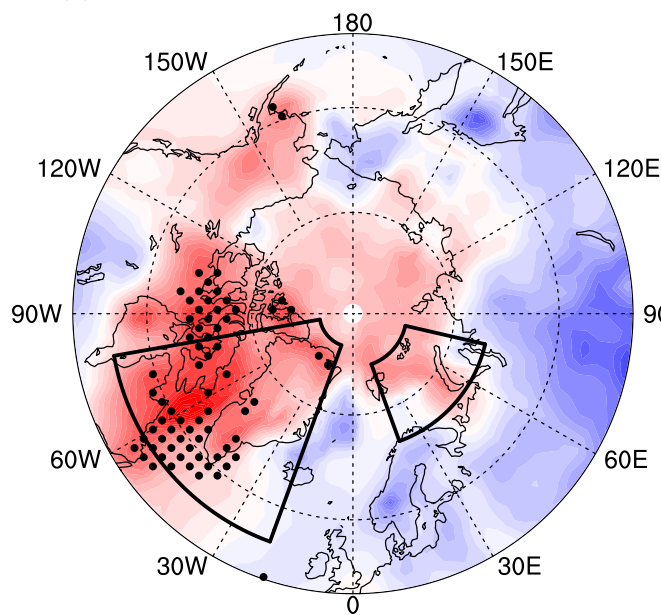

(b) EP_La Nina

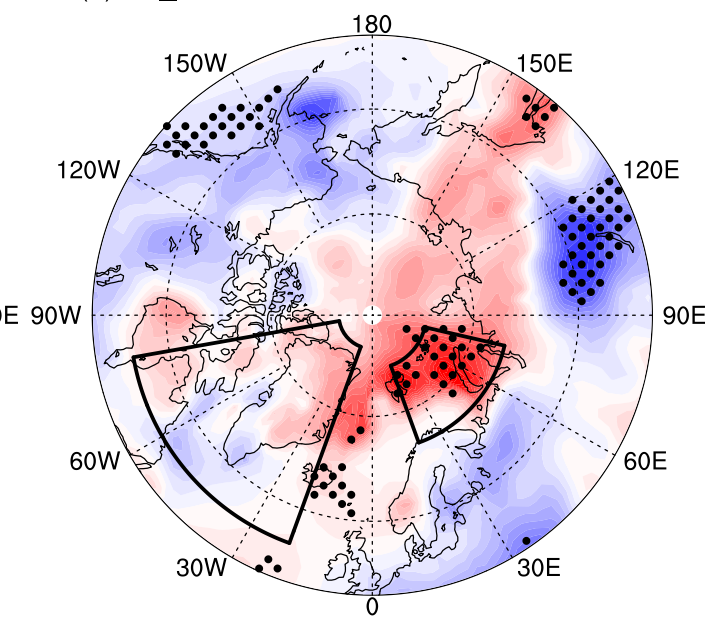

(d) CP_La Nina

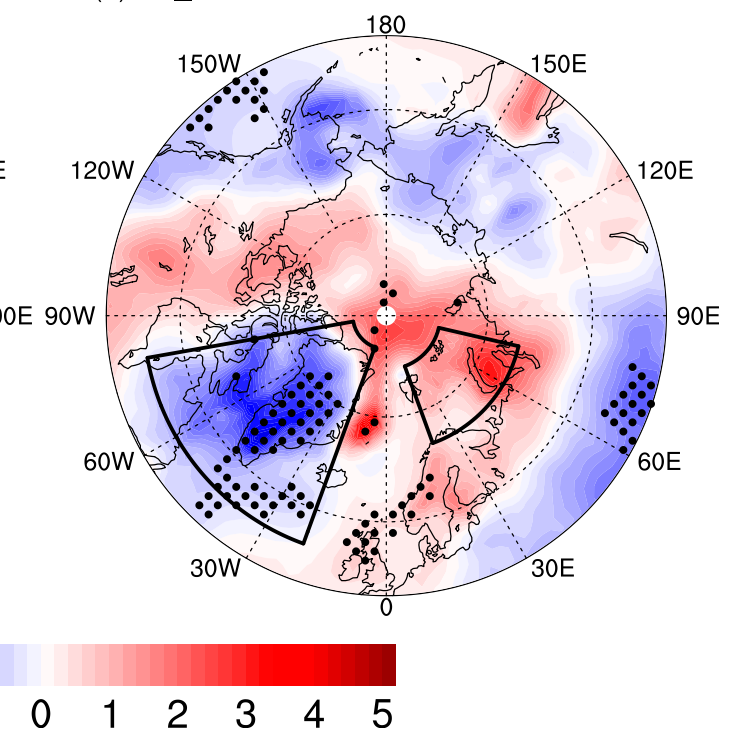

FIG. 3. As in Fig. 2, but for February 2-m temperature anomalies (shading; ${ }^{\circ} \mathrm{C}$ ) during (a) EP El Niño, (b) EP La Niña, (c) CP El Niño, and (d) CP La Niña events.

We also examine whether Arctic SAT responses to both ENSO warm and cold phases are similar to their linear response, respectively. Despite some regional signals in the linear ENSO responses occurring during either EP or CP January (Figs. 2a,b), almost no statistically significant responses are found during both EP and CP El Niño and La Niña except for northwestern North America (not shown). In February, the dominant positive SAT responses are located in northwestern North America and surrounding seas, and negative SAT responses are located in the Okhotsk Sea and the Barents-Kara Seas for EP El Niño (Fig. 3a). The SAT response to EP La Niña exhibits roughly the opposite sign (spatial correlation $=-0.61$ ) but with some differences over northwestern North America and the
Okhotsk Sea (Fig. 3b). For CP ENSO, the only significant SAT responses to CP El Niño and La Niña are found around northeastern Canada and Greenland, characterized by warm SAT anomalies over northeastern Canada and Greenland during CP El Niño (Fig. 3c) and cold SAT anomalies over Greenland during CP La Niña (Fig. 3d). The difference between EP and CP El Niño (La Niña) in February SAT responses is also examined and evaluated by a bootstrapped test and FDR test (Fig. 4). For El Niño events, the cold anomalies are significant over the Barents-Kara Seas and northeastern Canada and Greenland regions (Fig. 4a). Warm anomalies can be detected over these two regions in La Niña difference despite insignificant signal over the BarentsKara Seas (Fig. 4b). It seems that the difference in the 
(a) El Nino difference

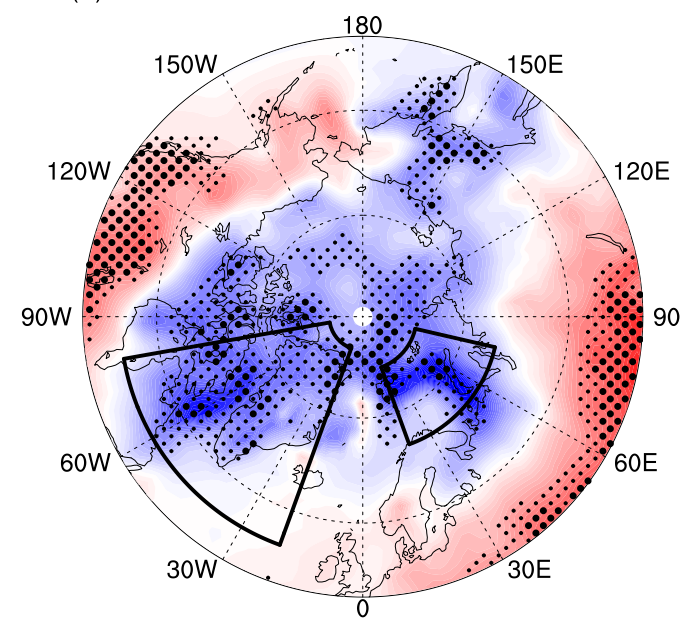

(b) La Nina difference

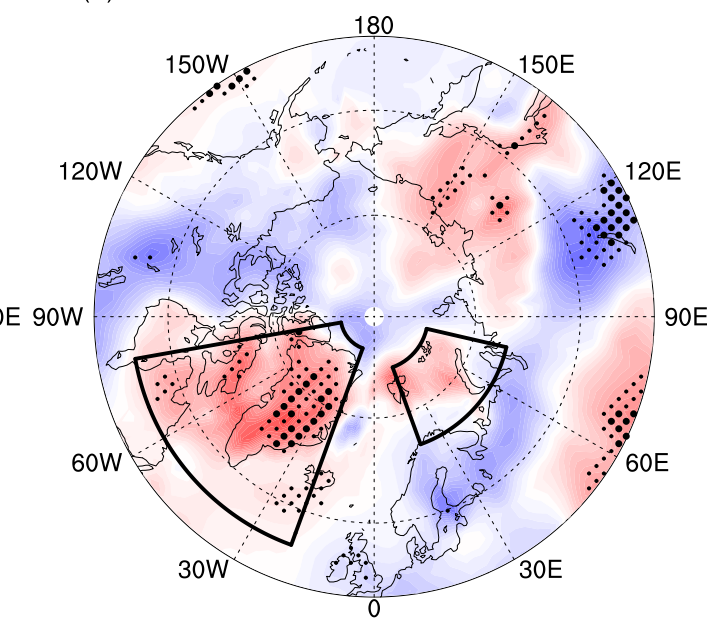

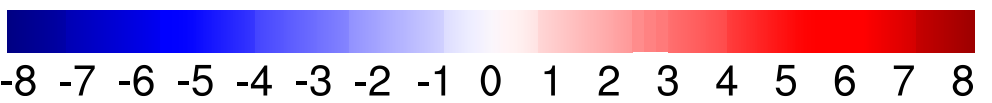

FIG. 4. Composites of 2-m temperature anomalies (shading; ${ }^{\circ} \mathrm{C}$ ) for (a) El Niño difference (EP El Niño minus CP El Niño) and (b) La Niña difference (EP La Niña minus CP La Niña) events during February. Small dots indicate the composites are statistically significant at the $90 \%$ confidence level. Big dots show global field significance based on the FDR approach with $\alpha_{\mathrm{FDR}}=0.2$. Black boxes outline the Barents-Kara Seas $\left(20^{\circ}-77^{\circ} \mathrm{E}, 70^{\circ}-82^{\circ} \mathrm{N}\right)$ and northeastern Canada and Greenland $\left(80^{\circ}-20^{\circ} \mathrm{W}, 55^{\circ}-85^{\circ} \mathrm{N}\right)$ regions, respectively.

linear ENSO response over the Barents-Kara Seas comes mainly from the difference between EP and CP El Niño.

The most pronounced differences in the SAT responses to the two ENSO types are located in two areas-northeastern Canada and Greenland $\left(80^{\circ}-20^{\circ} \mathrm{W}\right.$, $\left.55^{\circ}-85^{\circ} \mathrm{N}\right)$ and the Barents-Kara Seas $\left(20^{\circ}-77^{\circ} \mathrm{E}, 70^{\circ}-\right.$ $82^{\circ} \mathrm{N}$ ) indicated by boxes in Fig. 2. These are also the regions in the Arctic that exhibit pronounced warming rates in recent decades (Screen and Simmonds 2010; Ding et al. 2014; Khan et al. 2014; Jung et al. 2017). Hence, we emphasize in this study the Arctic SAT responses in these regions to different ENSO types. We show in Fig. 5 the SAT anomalies averaged over the Barents-Kara Seas for EP ENSO and over northeastern Canada and Greenland for CP ENSO from July of the developing ENSO year to the following June. The ENSO-associated SAT responses in these regions exhibit a strong seasonality. Consistent with Fig. 2, negative SAT anomalies over the Barents-Kara Seas are only statistically significant during EP ENSO February, while statistically significant positive SAT anomalies over northeastern Canada and Greenland during CP ENSO can be found from January to February (with smaller amplitude during January compared to February). No statistically significant signals can be detected for other months. A strong seasonality in ENSO teleconnections has also been mentioned in previous studies
(Fraedrich 1990; Moron and Gouirand 2003; Zhang et al. 2015, 2019; King et al. 2018a,b), for example, a varying ENSO teleconnection to the Euro-Atlantic sector between early and late boreal winter (King et al. 2018b). To investigate the possible mechanisms leading to these different Arctic climate anomalies associated with the two ENSO types, we hereafter emphasize the climate anomalies during February.

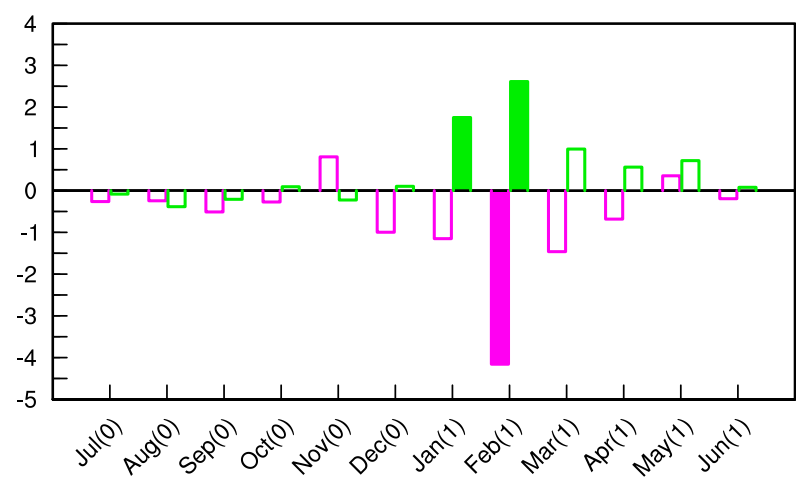

FIG. 5. Average of 2-m temperature anomalies $\left({ }^{\circ} \mathrm{C}\right)$ over the Barents-Kara Seas (purple) for EP ENSO (EP El Niño minus EP La Niña), and for over northeastern Canada and Greenland (green) for CP ENSO (CP El Niño minus CP La Niña) events from July of the developing ENSO event to the following June. Filled bars indicate statistical significance at the $90 \%$ confidence level. The number 0 in the parentheses denotes the developing ENSO year, and the number 1 denotes the following year. 


\section{(a) EP_ENSO}

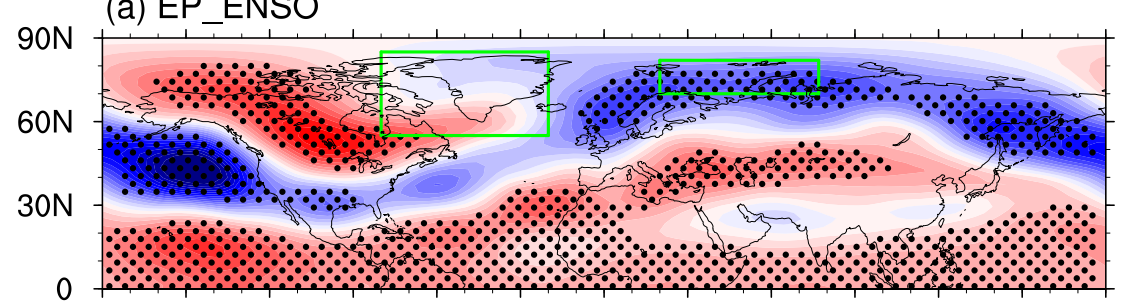

(b) CP_ENSO

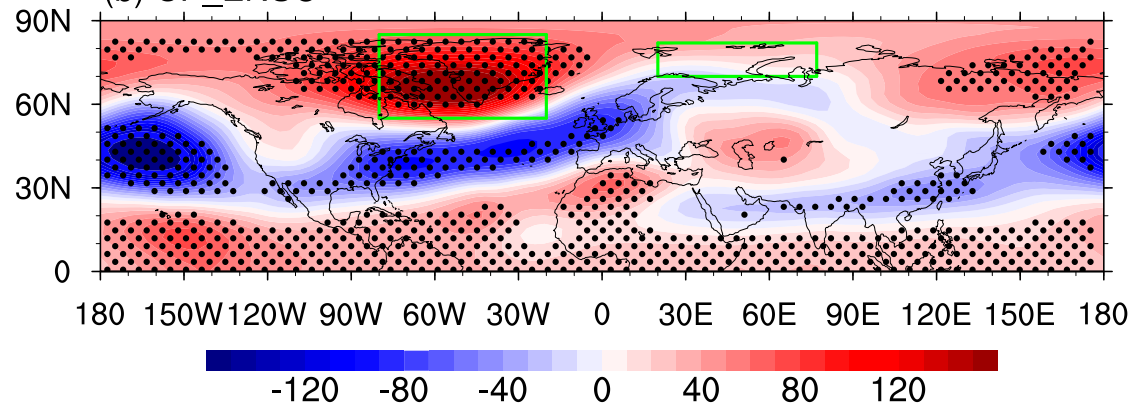

FIG. 6. Composites of the February 300-hPa geopotential height anomalies (shading; gpm) during (a) EP ENSO (EP El Niño minus EP La Niña) and (b) CP ENSO (CP El Niño minus CP La Niña) events. Stippling indicates values where the composites are statistically significant at the $90 \%$ confidence level. Green boxes outline the Barents-Kara Seas and northeastern Canada and Greenland regions, respectively.

\section{Possible mechanisms for different Arctic SAT responses to the two ENSO types}

\section{a. Large-scale teleconnection pattern and local atmospheric circulation}

The ENSO-associated convective anomalies in the tropical Pacific are accompanied by areas of strong divergence or convergence, respectively. These tropical atmospheric anomalies further lead to large-scale extratropical teleconnections via Rossby wave propagation (Hoskins and Karoly 1981; Wallace and Gutzler 1981). The two ENSO types exhibit different extratropical Rossby wave propagation pathways because of different convective anomalies in the tropical $\mathrm{Pa}$ cific (e.g., Hu et al. 2016a; Feng et al. 2017). To further explore the different Arctic responses, we show the large-scale circulation anomalies (300-hPa geopotential height) for the two ENSO types in Fig. 6. For EP ENSO, significant positive height anomalies are evident mainly over the tropics, North America, and Eurasia in the midlatitudes (Fig. 6a). For the two regions emphasized in this study (green boxes in Fig. 6), no statistically significant signal can be detected in northeastern Canada and Greenland, which may be associated with the nonlinear North Atlantic Oscillation (NAO) response to El Niño and La Niña (Zhang et al. 2019). Meanwhile, statistically significant negative height anomalies are found over the Barents-Kara Seas region during EP ENSO.
These negative height anomalies extend from the Atlantic to eastern Eurasia. They tend to enhance the regional tropospheric polar vortex over the Eurasian sector of the Arctic and are in favor of keeping cold air trapped in these regions. In contrast, the geopotential height response to CP ENSO exhibits positive anomalies over the polar low region and negative anomalies stretching from the North Pacific to the North Atlantic (Fig. 6b). Over the Atlantic and surrounding regions, the anomalous circulation resembles a negative NAO-like pattern, which may be associated with the linear relationship between CP ENSO and the NAO (Zhang et al. 2019). For the regions of concern here, statistically significantly positive geopotential height anomalies are located in northeastern Canada and Greenland, indicating a weakened regional tropospheric polar vortex. A weakened tropospheric polar vortex leads to enhanced meridional airmass exchange, usually accompanied by regional polar warming. In contrast, no significant geopotential height signal is found in the Barents-Kara Seas region. A simple tropospheric polar vortex index defined by averaging the geopotential height anomalies north of $65^{\circ} \mathrm{N}$ and between 500 and $300 \mathrm{hPa}$ also shows a similar relationship with the two ENSO types (not shown). Previous studies showed that EP ENSO events are typically accompanied by wave activity flux over the Barents-Kara Seas, while CP ENSO events coincide with strong wave activity flux 


\section{(a) El Nino difference}

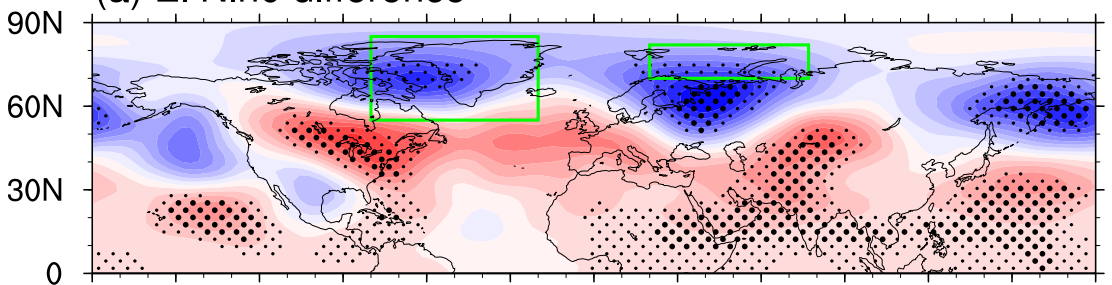

(b) La Nina difference

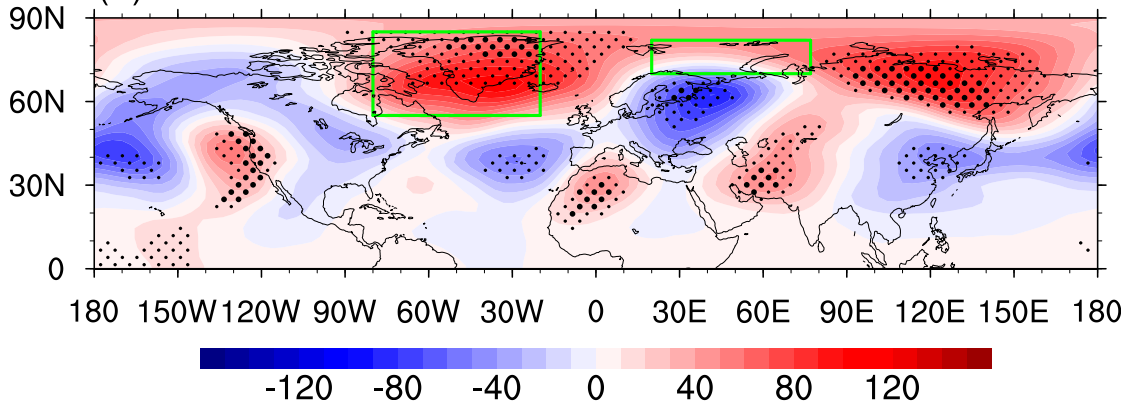

FIG. 7. Composites of 300-hPa geopotential height anomalies (shading; gpm) for (a) El Niño difference (EP El Niño minus CP El Niño) and (b) La Niña difference (EP La Niña minus CP La Niña) events during February. Small dots indicate the composites are statistically significant at the $90 \%$ confidence level. Big dots show global field significance based on the FDR approach with $\alpha_{\mathrm{FDR}}=0.2$. Green boxes outline the Barents-Kara Seas $\left(20^{\circ}-77^{\circ} \mathrm{E}, 70^{\circ}-82^{\circ} \mathrm{N}\right)$ and northeastern Canada and Greenland $\left(80^{\circ}-20^{\circ} \mathrm{W}, 55^{\circ}-85^{\circ} \mathrm{N}\right)$ regions, respectively.

over northeastern Canada and Greenland [see supplementary Fig. 5 in Hu et al. (2016a) and Figs. 6 and 10 in Feng et al. (2017)]. Furthermore, the difference between EP and CP El Niño (La Niña) related teleconnections is also displayed to examine whether there are different teleconnections associated with two types of ENSO (Fig. 7). Consistent with SAT responses, there are roughly opposite responses in $300-\mathrm{hPa}$ geopotential
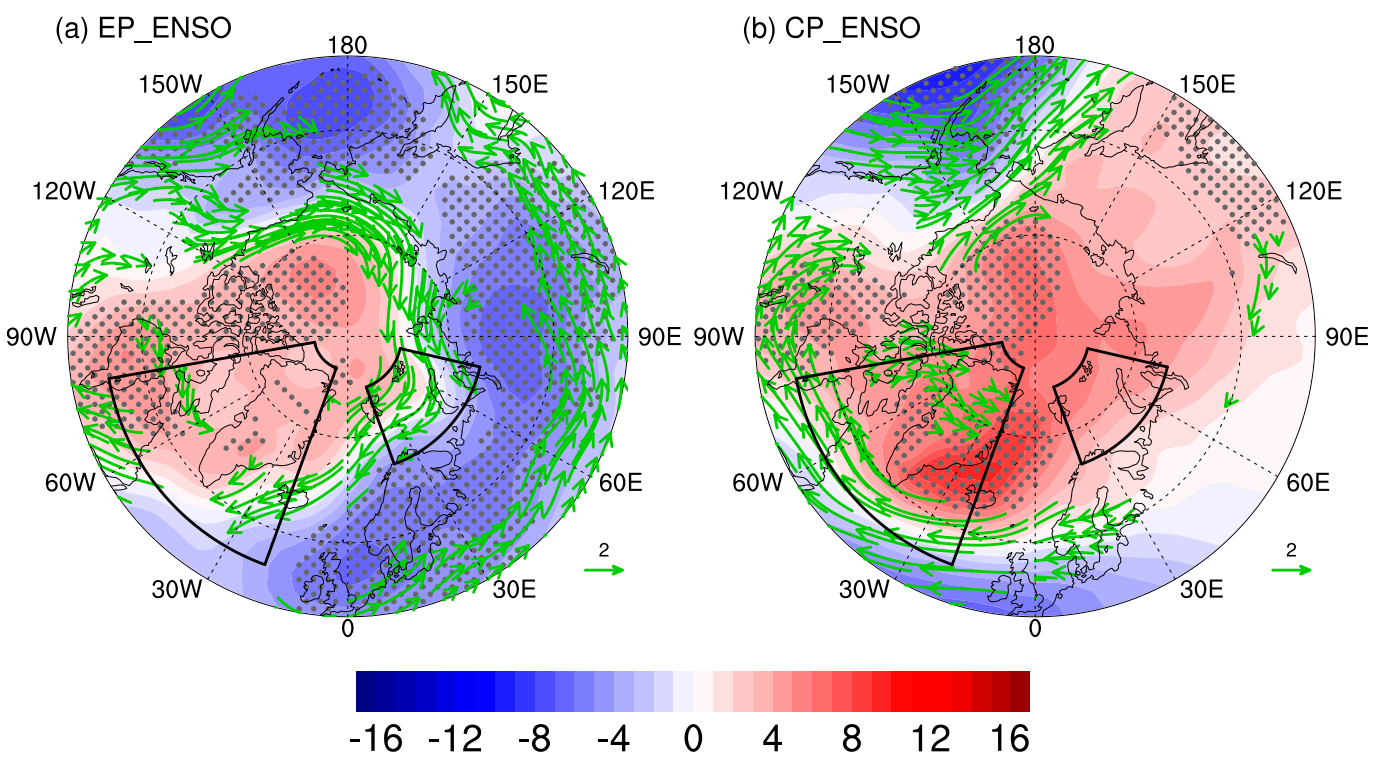

FIG. 8. Composites of the February sea level pressure (SLP; shading; hPa) and 850-hPa wind anomalies (vectors; $\mathrm{m} \mathrm{s}^{-1}$ ) during (a) EP ENSO (EP El Niño minus EP La Niña) and (b) CP ENSO (CP El Niño minus CP La Niña) events. Stippling indicates values where the composites are statistically significant at the $90 \%$ confidence level. The $850-\mathrm{hPa}$ wind anomalies are shown only when the anomalous zonal or meridional wind is statistically significant at the $80 \%$ confidence level. Black boxes outline the Barents-Kara Seas and northeastern Canada and Greenland regions, respectively. 
height for El Niño and La Niña difference, except for insignificant signal over the Barents-Kara Seas in $\mathrm{EP} / \mathrm{CP}$ La Niña difference.

We next examine the low-level atmospheric circulation anomalies and focus on the Arctic region to explore the role of dynamic processes (Fig. 8). During EP ENSO February, positive SLP anomalies cover northeastern North America and Greenland and negative SLP anomalies stretch eastward from the Norway Sea to the Bering Sea (Fig. 8a). The Barents-Kara Seas, being a transition region between anomalous high and low pressure zones, are mainly affected by northeasterly wind anomalies. The southeastern part of Greenland is also affected by northeasterly wind. These northeasterly anomalies advect relatively colder air into the two key regions. The Barents-Kara Seas exhibit statistically significant cold SAT advection during EP ENSO (Fig. 9a), resulting in negative SAT anomalies (Fig. 2c). Northeastern Canada and Greenland are also dominated by weak cold SAT advection during EP ENSO February (Fig. 9a). Compared with EP ENSO, the SLP pattern of CP ENSO mainly exhibits positive anomalies, except for negative anomalies in the Bering Sea and the North Atlantic Ocean (Fig. 8b). Controlled by high pressure, northeastern Canada and Greenland are dominated by anticyclonic circulation. The southern part of this region is largely characterized by southeasterly winds, while northern Greenland $\left(\sim 75^{\circ} \mathrm{N}, 60^{\circ}-\right.$ $\left.30^{\circ} \mathrm{W}\right)$ exhibits southwesterly surface wind anomalies, bringing warm and moist air from the North Atlantic to the Arctic. No statistically significant wind anomalies can be detected over the Barents-Kara Seas for CP ENSO. Correspondingly, positive temperature advection anomalies are evident over northeastern Canada and Greenland during CP ENSO, while no statistically significant signals can be seen in the Barents-Kara Seas (Fig. 9a).

We also examine the contribution of adiabatic warming. Weak adiabatic warming is observed in both regions, the Barents-Kara Seas as well as northeastern Canada and Greenland, during EP ENSO (Fig. 9b), while no statistically significant adiabatic warming over the Barents-Kara Seas and statistically significant adiabatic cooling over northeastern Canada and Greenland are found during CP ENSO (Fig. 9b). In comparison, the contribution of adiabatic warming/cooling to the SAT anomalies is much smaller than the contribution of horizontal temperature advection.

\section{b. Potential local water vapor-cloud-radiation feedback}

The above analyses suggest that poleward-propagating Rossby waves excited by tropical Pacific heating can
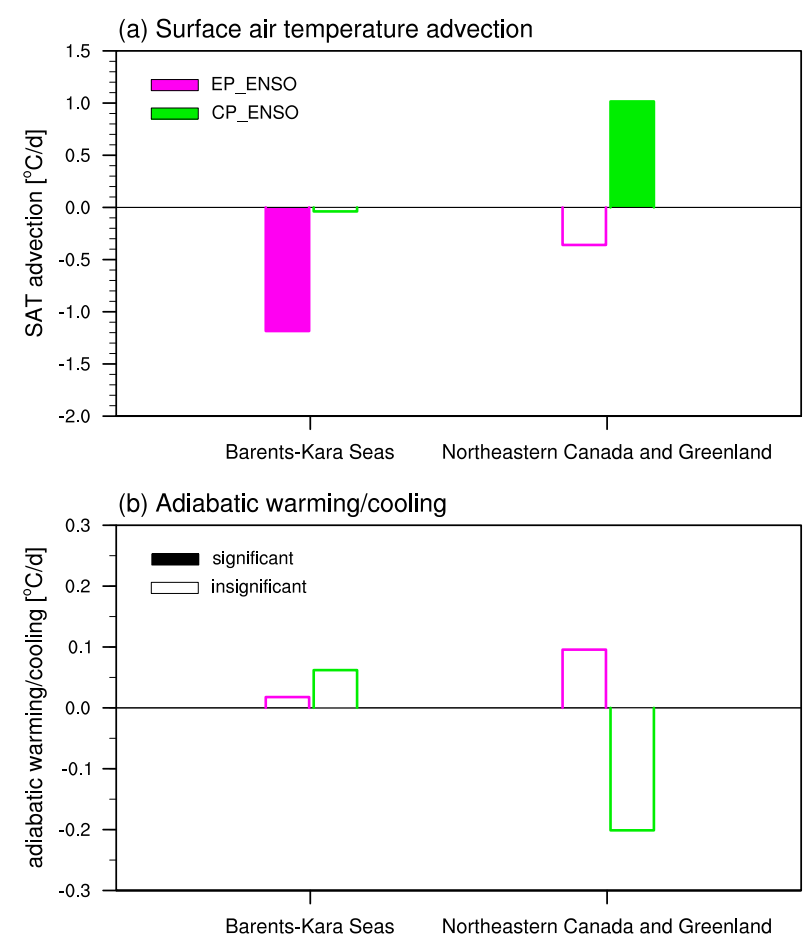

FIG. 9. Average of (a) surface air temperature advection $\left({ }^{\circ} \mathrm{C}\right.$ day $\left.^{-1}\right)$ and (b) adiabatic warming/cooling anomalies $\left({ }^{\circ} \mathrm{C} \mathrm{day}{ }^{-1}\right)$ over the Barents-Kara Seas and northeastern Canada and Greenland regions for EP ENSO (EP El Niño minus EP La Niña; purple), and CP ENSO (CP El Niño minus CP La Niña; green) events. Filled bars indicate statistical significance at the $90 \%$ confidence level.

warm/cool the Arctic directly via dynamic processes (i.e., horizontal temperature advection and vertical adiabatic processes). The warming and cooling of the surface are accompanied by local water vapor changes, which in turn could affect local cloud cover and thus local downward infrared radiation (IR) (Lee et al. 2011a,b; Lee 2012, 2014). Increased cloud cover and positive downward IR anomalies tend to increase SAT in the Arctic. Considering the importance of Arctic clouds on local SAT, both cloud-cover anomalies and associated downward IR anomalies are shown in Fig. 10. Corresponding to the different tropical heating sources of the two ENSO types, the water vapor anomaly patterns (Figs. 10a,d) are highly consistent with the SAT patterns (Figs. 2c,d). For the two key regions of concern, negative water vapor anomalies are evident in the Barents-Kara Seas during EP ENSO (Fig. 10a) and positive water vapor anomalies over northeastern Canada and Greenland during CP ENSO (Fig. 10d). The negative water vapor anomalies (associated with dynamic sinking, not shown) in the Barents-Kara Sea might lead to reduced cloud cover during EP ENSO (Fig. 10b) and thus to a reduction in downwelling IR 

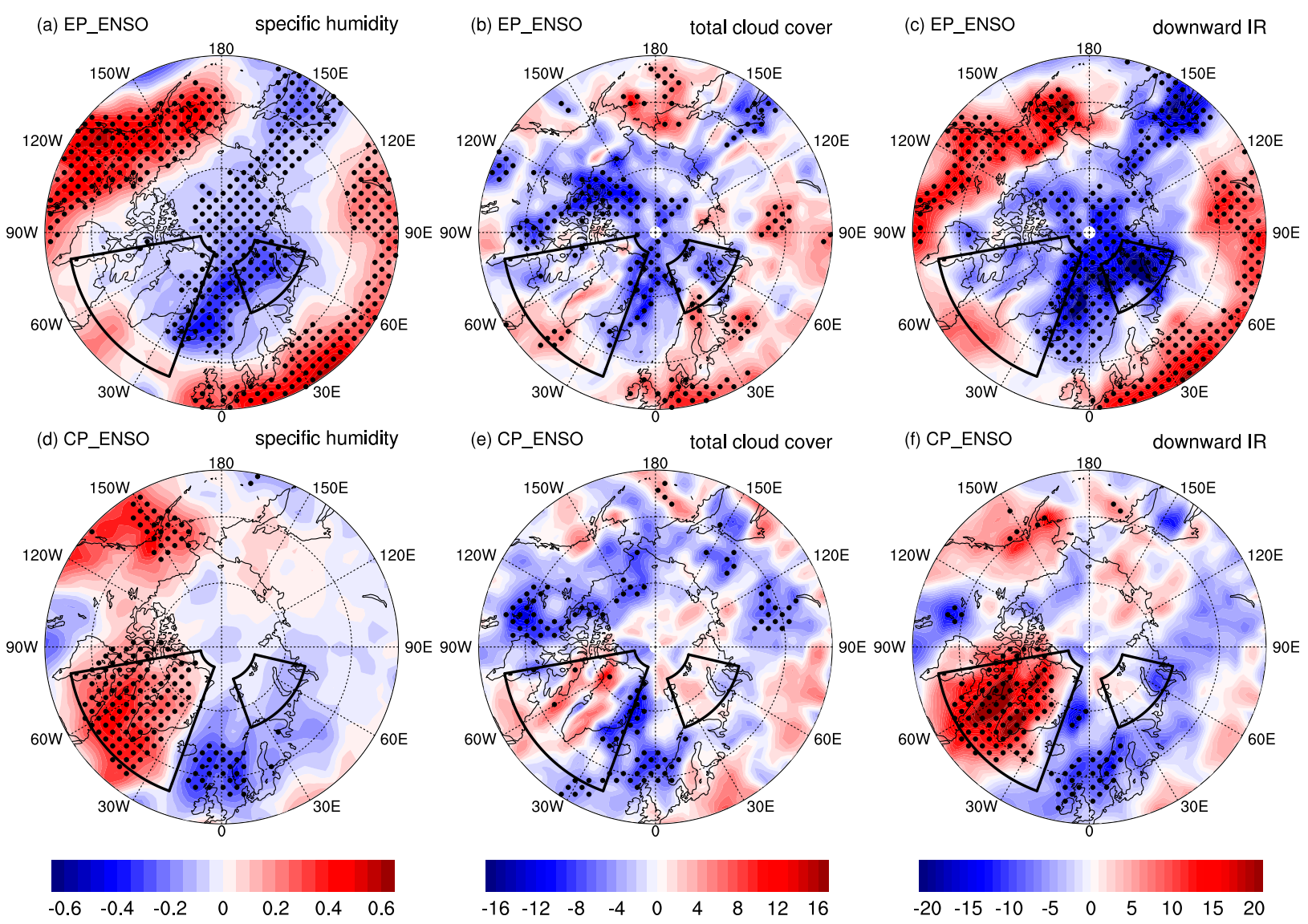

FIG. 10. As in Fig. 8, but for (a),(d) 850-hPa specific humidity (shading; $\mathrm{g} \mathrm{kg}^{-1}$ ), (b),(e) total cloud cover (shading; \%), and (c),(f) downward IR (shading; $\mathrm{W} \mathrm{m}^{-2}$ ).

(Fig. 10c), which in turn could further decrease SAT. In contrast, positive water vapor anomalies (associated with dynamic lifting, not shown) might lead to increased cloud cover and positive downwelling IR anomalies in northeastern Canada and Greenland during CP ENSO (Figs. 10e,f), which in turn could further increase SAT. Thus, water vapor-cloud-IR feedback might enhance local SAT anomalies in the Arctic region.

\section{c. Simulating the observed Arctic SAT response}

We utilize a series of atmospheric general circulation model (AGCM) experiments to test if the observed Arctic SAT responses to tropical SST anomalies associated with different ENSO types can be simulated (experiments listed in Table 2 and described in section 2c). Figure 11 shows the simulated February Arctic SAT anomalies in response to the tropical Pacific SST anomalies for the two different ENSO types. The observed Arctic SAT anomaly patterns can be well reproduced by these simulations (Fig. 11). For example, statistically significant positive SAT anomalies are reasonably simulated over the northwestern North America region in the EP ENSO (EP El Niño minus EP La Niña) and CP ENSO (CP El Niño minus CP La Niña) experiments. For the two key regions, the experiments can produce statistically significant negative SAT anomalies in the Barents-Kara Seas during EP ENSO (Fig. 11a) and statistically significant positive SAT anomalies over northeastern Canada and Greenland during CP ENSO (Fig. 11b), largely consistent with the observations. As for the EP and CP El Niño (La Niña) difference, significant cold (warm) anomalies over the regions of interest can also be captured by the AM2.1 simulation despite some uncertainties (Fig. 12).

To examine the large-scale teleconnections excited by the tropical Pacific SST anomalies, we show in Fig. 13 the simulated $300-\mathrm{hPa}$ geopotential height anomalies for the two ENSO types. The observed teleconnection patterns (Fig. 6) can be well reproduced in these experiments (Fig. 13). For the key regions, negative geopotential height anomalies in the Barents-Kara Seas can be realistically reproduced with EP ENSO SST anomaly forcing, however, with weaker amplitude compared to the observations. Geopotential height anomalies over 
(a) EP_ENSO

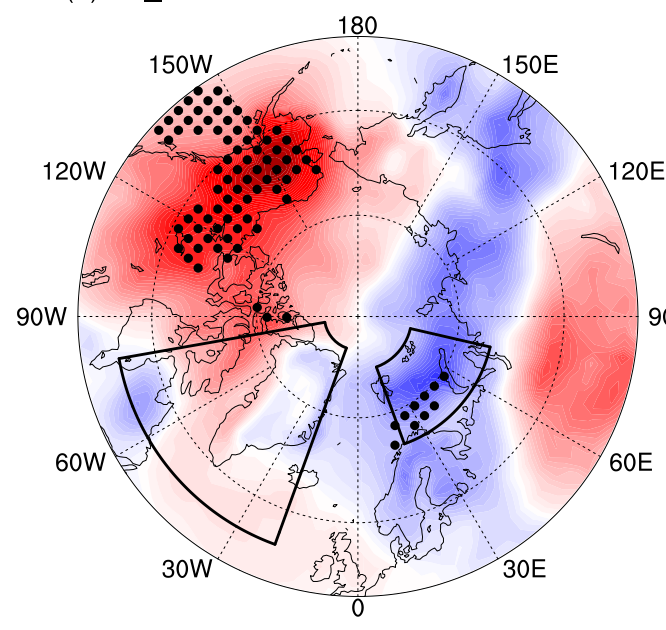

(b) CP ENSO

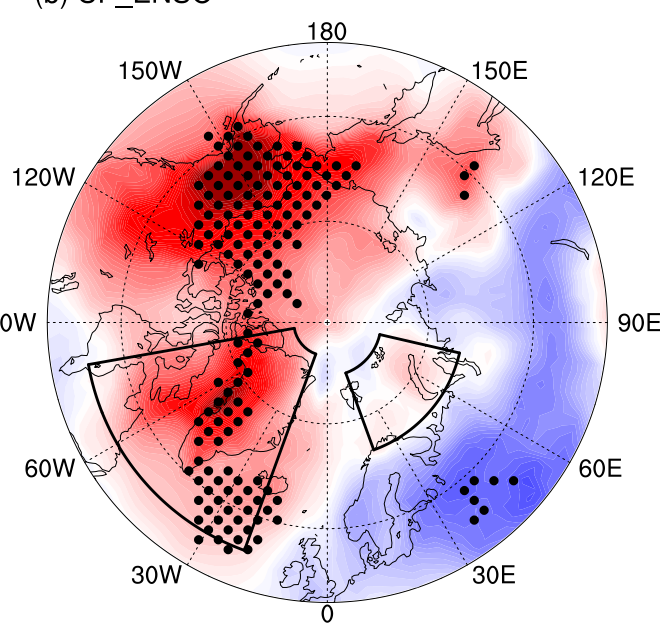

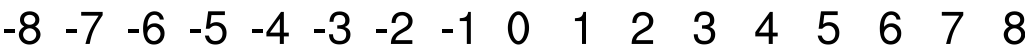

FIG. 11. Simulated ensemble mean February SAT $\left({ }^{\circ} \mathrm{C}\right)$ in response to the tropical Pacific SST anomaly forcing of (a) EP ENSO (EP El Niño minus EP La Niña) and (b) CP ENSO (CP El Niño minus CP La Niña). Stippling indicates values where the composites are statistically significant at the $90 \%$ confidence level. Black boxes outline the Barents-Kara Seas and northeastern Canada and Greenland regions, respectively.

northeastern Canada and Greenland are not statistically significant (Fig. 13a), consistent with the observations (Fig. 6a). In response to CP ENSO SST anomaly forcing, the Arctic region shows positive geopotential height anomalies that are statistically significant over northeastern Canada and Greenland and insignificant over the Barents-Kara Seas (Fig. 13b). The difference of $\mathrm{EP} / \mathrm{CP} \mathrm{El}$ Niño and that of EP/CP La Niña in (a) El Nino difference

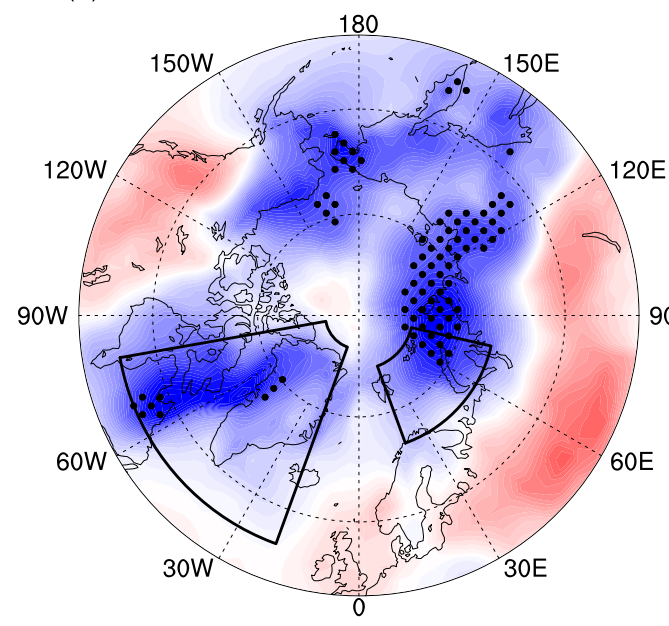

(b) La Nina difference

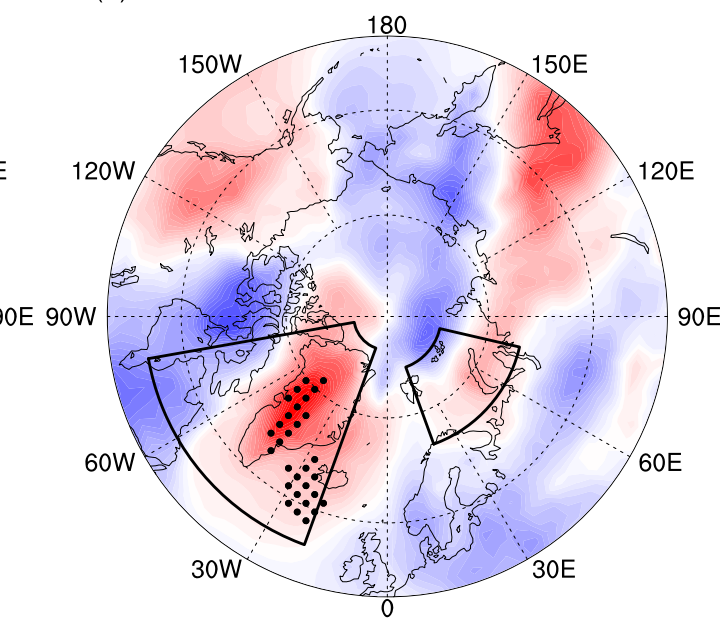

$\begin{array}{lllllllllllllllll}-8 & -7 & -6 & -5 & -4 & -3 & -2 & -1 & 0 & 1 & 2 & 3 & 4 & 5 & 6 & 7 & 8\end{array}$

FIG. 12. Simulated ensemble mean February SAT $\left({ }^{\circ} \mathrm{C}\right)$ in response to the tropical Pacific SST anomaly forcing of (a) El Niño (EP El Niño minus CP El Niño) and (b) La Niña (EP La Niña minus CP La Niña). Stippling indicates values where the composites are statistically significant at the $90 \%$ confidence level. Black boxes outline the Barents-Kara Seas $\left(20^{\circ}-77^{\circ} \mathrm{E}, 70^{\circ}-82^{\circ} \mathrm{N}\right)$ and northeastern Canada and Greenland $\left(80^{\circ}-20^{\circ} \mathrm{W}, 55^{\circ}-85^{\circ} \mathrm{N}\right)$ regions, respectively. 


\section{(a) EP_ENSO}

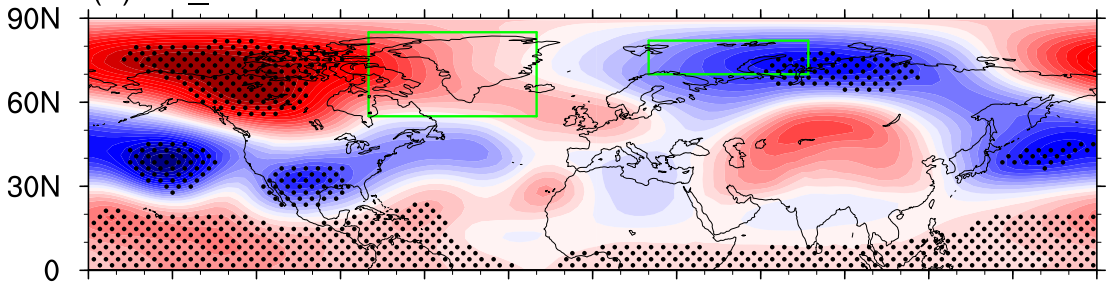

(b) CP_ENSO

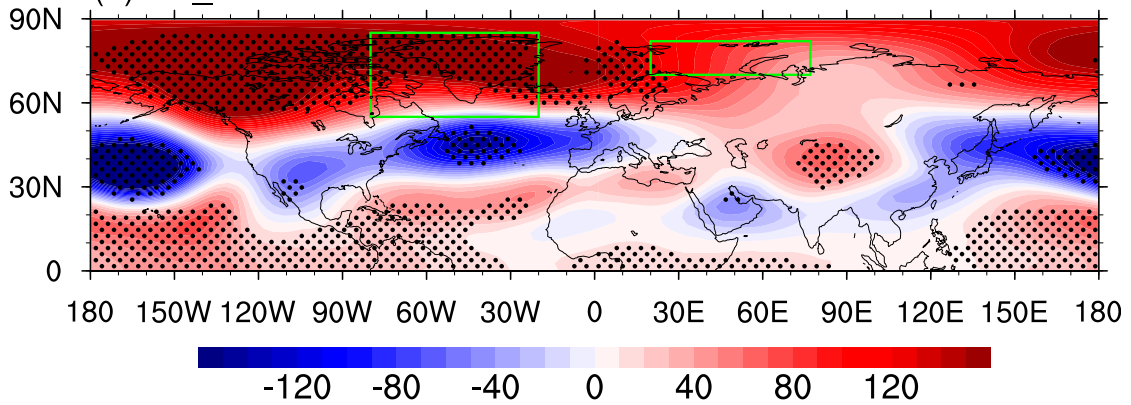

FIG. 13. Simulated ensemble mean February 300-hPa geopotential height (shading; gpm) in response to the tropical Pacific SST anomaly forcing of (a) EP ENSO (EP El Niño minus EP La Niña) and (b) CP ENSO (CP El Niño minus CP La Niña). Stippling indicates values where the composites are statistically significant at the $90 \%$ confidence level. Green boxes outline the Barents-Kara Seas and northeastern Canada and Greenland regions, respectively.

teleconnection are also compared. Similar to the observation, differences in 300-hPa geopotential height anomalies can be clearly seen over the key regions in our study despite of insignificant signal over northeastern
Canada and Greenland in the EP/CP El Niño difference and over the Barents-Kara Seas in the EP/CP La Niña difference (Fig. 14). These model simulations generally support our hypothesis that the tropical Pacific heating

\section{(a) El Nino difference}

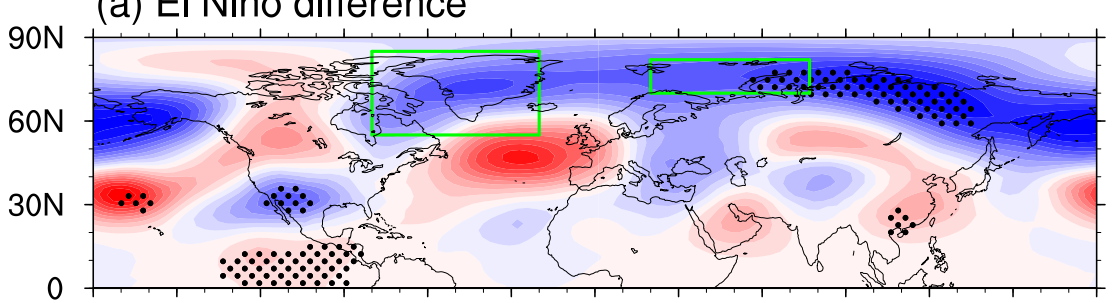

(b) La Nina difference

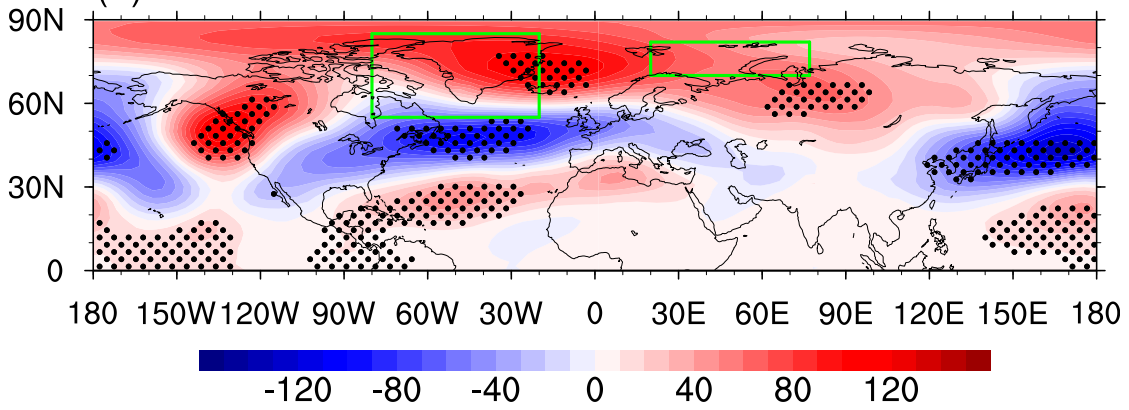

FIG. 14. Simulated ensemble mean February 300-hPa geopotential height (shading; gpm) in response to the tropical Pacific SST anomaly forcing of (a) El Niño (EP El Niño minus CP El Niño) and (b) La Niña (EP La Niña minus CP La Niña). Stippling indicates values where the composites are statistically significant at the $90 \%$ confidence level. Green boxes outline the Barents-Kara Seas $\left(20^{\circ}-77^{\circ} \mathrm{E}, 70^{\circ}-82^{\circ} \mathrm{N}\right)$ and northeastern Canada and Greenland $\left(80^{\circ}-20^{\circ} \mathrm{W}, 55^{\circ}-85^{\circ} \mathrm{N}\right)$ regions, respectively. 
(a) EP_ENSO

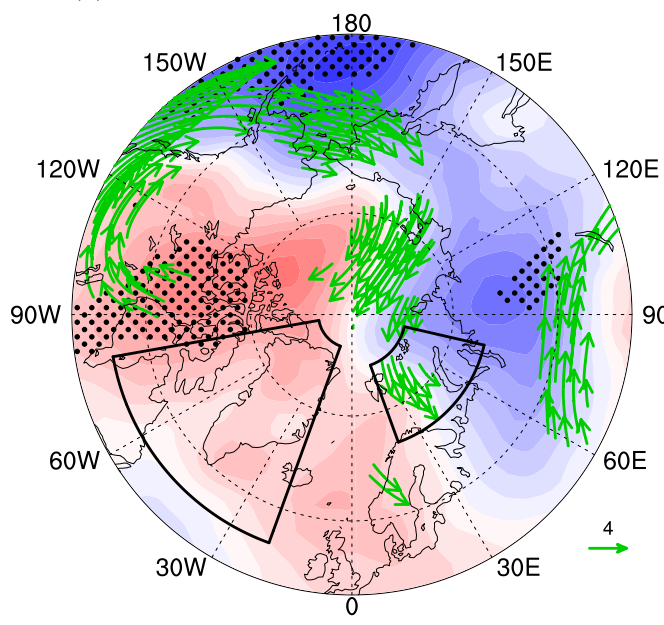

(b) CP_ENSO

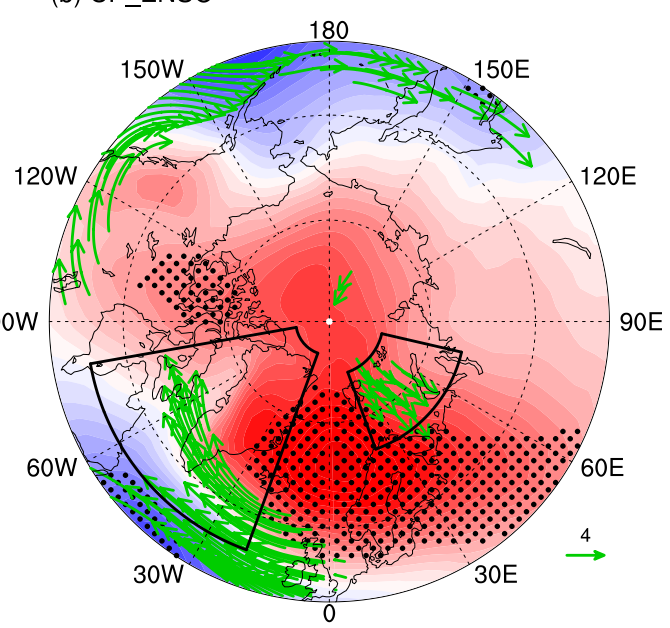

$$
\begin{array}{lllllllllll}
-20 & -16 & -12 & -8 & -4 & 0 & 4 & 8 & 12 & 16 & 20
\end{array}
$$

FIG. 15. As in Fig. 11, but for SLP (shading; hPa) and 850-hPa wind (vectors; $\mathrm{m} \mathrm{s}^{-1}$ ). The 850-hPa wind anomalies are shown only when either the anomalous zonal or meridional wind is statistically significant at the $90 \%$ confidence level.

associated with the two ENSO types can result in very different atmospheric responses in the Arctic region during boreal winter.

We next examine the simulated local low-level atmospheric circulation and potential local water vaporcloud-IR feedback. The model simulations are largely able to reproduce the general patterns of SLP and 850$\mathrm{hPa}$ winds seen in the observations during EP and CP ENSO events (Fig. 15). Relative to the observations, the simulated anomalous SLP responses are weaker and the extent of negative SLP anomalies is reduced in the EP ENSO SST experiment. The simulated low-level water vapor anomalies are also consistent with the observations (Figs. 16a,c). Much drier conditions are simulated over the Barents-Kara Seas during EP ENSO (Fig. 16a), and wetter conditions are simulated over northeastern Canada and Greenland during CP ENSO (Fig. 16c). The enhanced water vapor favors an increase in total cloud cover, leading to positive downward IR anomalies and in turn further surface warming, while less water vapor favors a decrease in clouds, leading to negative downward IR anomalies and in turn further surface cooling (Figs. 16b,d). The model simulations can largely reproduce the observed local atmospheric response, including changes in water vapor, clouds, and IR radiation that are consistent with a vapor-cloud-IR feedback. The experiments can also reproduce a strong seasonality of the ENSO-associated Arctic SAT response (Fig. 17). However, the simulated seasonality differs from the observations (except in February), indicating difficulties of simulating seasonal differences of the ENSO-associated
Arctic response in this model and/or a low signal-tonoise ratio in the observations during the other months. For example, the simulated pronounced negative SAT anomalies during EP ENSO December over the Barents-Kara Seas and positive SAT anomalies in March in this region are absent in the observations. It is notable that we specify SST anomalies in the tropical Pacific only from October (0) to February (1) and SST anomalies are zero during other months (the number 0 in the parentheses denotes the developing ENSO year, and the number 1 denotes the following year). Thus, the SAT anomalies simulated in July (0)-September (0) and April (1)-June (1) are very small and result from internal atmospheric variability. The statistically significant SAT anomalies that simulated for March (1) are possibly due to a residual delayed effect of the SST anomaly forcing in February (1).

\section{Conclusions and discussion}

We investigated the different responses of Arctic SAT to two different ENSO types based on reanalysis datasets and model experiments. In February, EP ENSO events are accompanied by statistically significant composite SAT anomalies over the Barents-Kara Seas (negative SAT anomalies during El Niño and positive SAT anomalies during La Niña), while CP ENSO events are accompanied by statistically significant SAT anomalies over northeastern Canada and Greenland (positive SAT anomalies during El Niño and negative SAT anomalies during La Niña). The different Arctic SAT 
(a) EP ENSO

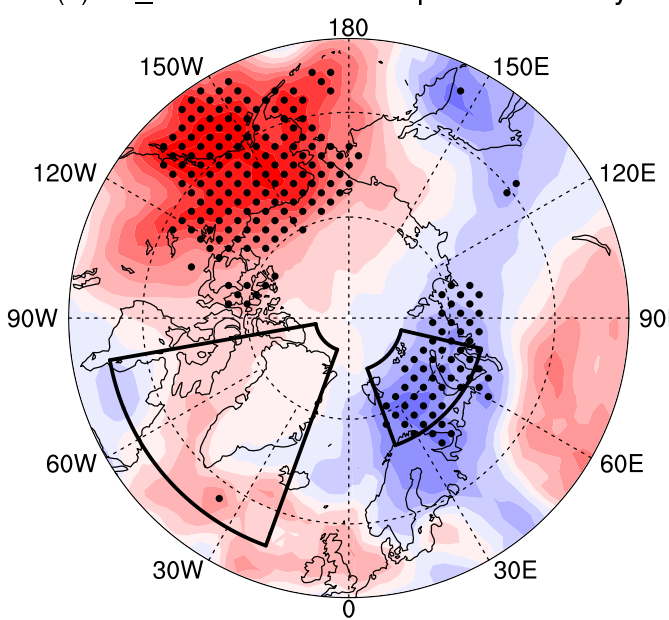

(c) CP_ENSO
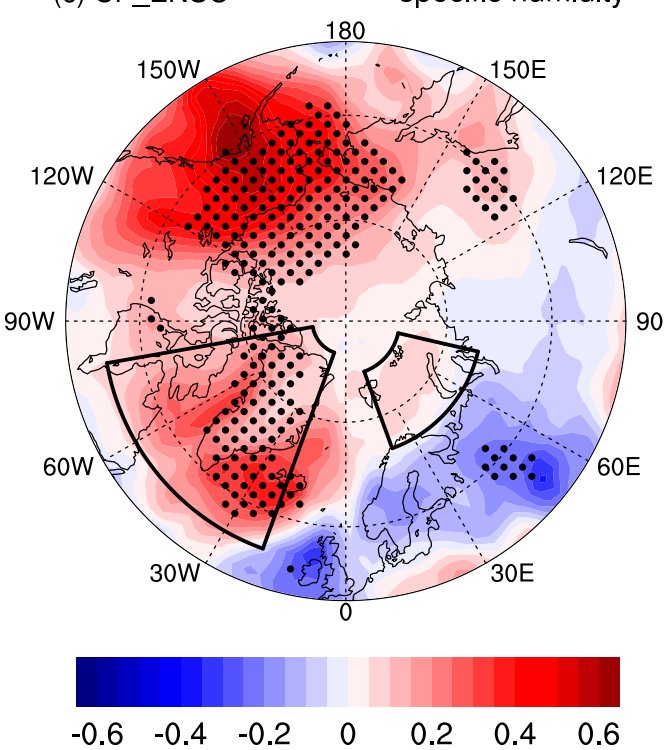

(b) EP ENSO

downward IR

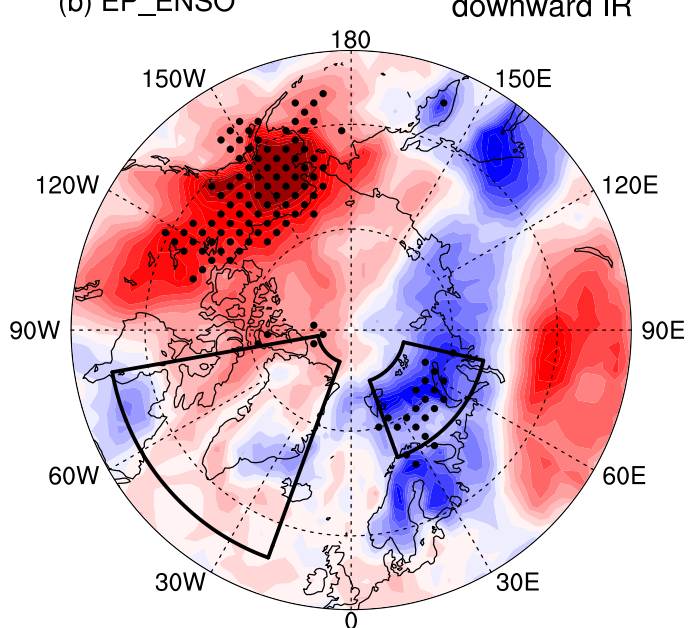

(d) CP_ENSO
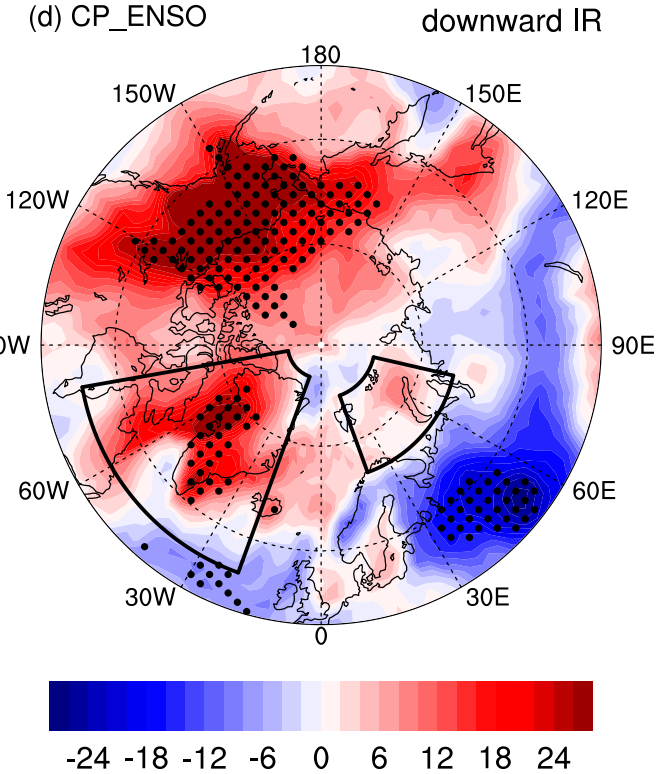

FIG. 16. As in Fig. 11, but for (a),(c) 850-hPa specific humidity (shading; $\mathrm{g} \mathrm{kg}^{-1}$ ) and (b),(d) downward IR (shading; $\mathrm{W} \mathrm{m}^{-2}$ ).

responses to the two ENSO types can be attributed to different large-scale teleconnection patterns via Rossby wave propagations, especially over the mid- and high latitudes. During EP ENSO February, statistically significant negative geopotential height anomalies can be found over the Barents-Kara Seas and the surrounding regions. The enhanced regional tropospheric polar vortex over the Eurasian sector of the Arctic and associated low-level northeasterly wind anomalies lead to colder-than-normal SAT over the Barents-Kara Seas, which is probably further enhanced by water vaporcloud-radiation feedback. During CP ENSO February, the tropospheric polar vortex is weakened, and the associated southwesterly wind anomalies tend to increase SAT over northeastern Canada and Greenland. The positive SAT anomalies might then be further enhanced by the water vapor-cloud-radiation feedback. Importantly, the ENSO-associated SAT responses exhibit a strong seasonality, especially the different responses between January and February. As Geng et al. (2017) mentioned, the climatological jet exhibits a southward movement during early January, giving rise to a different pathway for Rossby waves propagating eastward into the North Atlantic. Thus, seasonal changes of the background state could play an important role in the different teleconnection patterns associated with tropical diabatic heating. However, this hypothesis needs to be further investigated in the future.

A series of atmospheric general circulation model experiments with GFDL AM2.1 are able to reproduce 


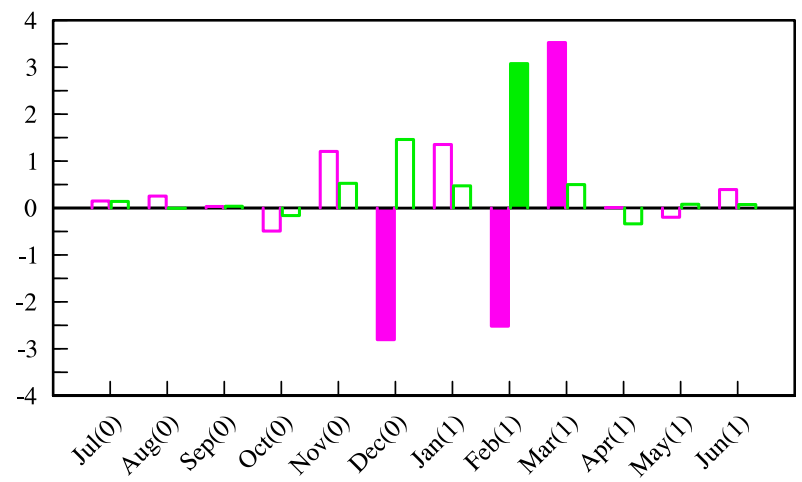

FIG. 17. Simulated ensemble mean 2-m temperature response $\left({ }^{\circ} \mathrm{C}\right)$ over the Barents-Kara Seas (purple) to the tropical Pacific SST anomaly forcing of EP ENSO (EP El Niño minus EP La Niña), and over northeastern Canada and Greenland (green) to the tropical Pacific SST anomaly forcing of CP ENSO (CP El Niño minus CP La Niña) from July of the developing ENSO event to the following June. Filled bars indicate statistical significance at the $90 \%$ confidence level. The number 0 in the parentheses denotes the developing ENSO year, and the number 1 denotes the following year.

the general observed features in the Arctic (large-scale teleconnection patterns and local atmospheric responses, as well as changes in water vapor, clouds, and radiation that are consistent with a feedback) in response to prescribed tropical ENSO SST anomaly forcing. This suggests that seasonal ENSO forecasts could potentially provide valuable information for Arctic SAT in February. However, the model utilized here shows a poor performance in reproducing the seasonality of ENSO-associated local Arctic SAT responses in other months than February. This might be explained by a low signal-to-noise ratio during other months over the high-latitude regions and/or climatological model biases.

In this study, we did not investigate potential impacts of the ice-albedo feedback. We expect that this feedback would further amplify the Arctic SAT response seen in our AGCM experiments. As CP ENSO events became more frequent (compared to EP ENSO events) since the 1990s (McPhaden et al. 2011; Zhang et al. 2014), this might explain some of the regional observed Arctic warming and sea ice changes, in addition to the greenhouse gas-forced long-term pan-Arctic warming trend that is dominated by observed regional Arctic forcing and feedbacks (Stuecker et al. 2018).

Acknowledgments. This work is supported by the National Key Research and Development Program (2018YFC1506002), the National Natural Science Foundation of China (41675073, 41490643, 41475086), the Jiangsu Provincial “333” project (BRA2015290), and the
Innovation project of Jiangsu Province (KYLX16_0927). M.F.S. was supported by the Institute for Basic Science (project code IBS-R028-D1).

\section{REFERENCES}

An, S. I., and B. Wang, 2000: Interdecadal change of the structure of the ENSO mode and its impact on the ENSO frequency. J. Climate, 13, 2044-2055, https://doi.org/10.1175/ 1520-0442(2000)013<2044:ICOTSO > 2.0.CO;2.

Anderson J. L., and Coauthors, 2004: The new GFDL global atmosphere and land model AM2-LM2: Evaluation with prescribed SST simulations. J. Climate, 17, 4641-4673, https:// doi.org/10.1175/JCLI-3223.1.

Ashok, K., S. K. Behera, S. A. Rao, H. Weng, and T. Yamagata, 2007: El Niño Modoki and its possible teleconnection. J. Geophys. Res., 112, C11007, https://doi.org/10.1029/ 2006JC003798.

Barnes, E. A., 2013: Revisiting the evidence linking Arctic amplification to extreme weather in midlatitudes. Geophys. Res. Lett., 40, 4734-4739, https://doi.org/10.1002/grl.50880.

— midlatitude jet-stream: Can it? Has it? Will it? Wiley Interdiscip. Rev.: Climate Change, 6, 277-286, https://doi.org/ 10.1002/wcc.337.

Bjerknes, J., 1969: Atmospheric teleconnections from the equatorial pacific. Mon. Wea. Rev., 97, 163-172, https://doi.org/ 10.1175/1520-0493(1969)097<0163:ATFTEP > 2.3.CO;2.

Budyko, M. I., 1969: The effect of solar radiation variations on the climate of the earth. Tellus, 21A, 611-619, https://doi.org/ 10.1111/j.2153-3490.1969.tb00466.x.

Cai, M., 2005: Dynamical amplification of polar warming. Geophys. Res. Lett., 32, L22710, https://doi.org/10.1029/2005GL024481.

_ 2006: Dynamical greenhouse-plus feedback and polar warming amplification. Part I: A dry radiative-transportive climate model. Climate Dyn., 26, 661-675, https://doi.org/ 10.1007/s00382-005-0104-6.

Cai, W. J., and T. Cowan, 2009: La Niña Modoki impacts Australia autumn rainfall variability. Geophys. Res. Lett., 36, L12805, https://doi.org/10.1029/2009GL037885.

Chen, M., P. Xie, J. E. Janowiak, and P. A. Arkin, 2002: Global land precipitation: A 50-yr monthly analysis based on gauge observations. J. Hydrometeor., 3, 249-266, https://doi.org/ 10.1175/1525-7541(2002)003<0249:GLPAYM>2.0.CO;2.

Cohen, J., 2016: An observational analysis: Tropical relative to Arctic influence on midlatitude weather in the era of Arctic amplification. Geophys. Res. Lett., 43, 5287-5294, https:// doi.org/10.1002/2016GL069102.

— treme mid-latitude weather. Nat. Geosci., 7, 627-637, https:// doi.org/10.1038/ngeo2234.

— , K. Pfeiffer, and J. A. Francis, 2018: Warm Arctic episodes linked with increased frequency of extreme winter weather in the United States. Nat. Commun., 9, 869, https://doi.org/ 10.1038/s41467-018-02992-9.

Coumou, D., G. Di Capua, S. Vavrus, L. Wang, and S. Wang, 2018: The influence of Arctic amplification on mid-latitude summer circulation. Nat. Commun., 9, 2959, https://doi.org/10.1038/ s41467-018-05256-8.

Deng, Y., T. W. Park, and M. Cai, 2012: Process-based decomposition of the global surface temperature response to El Niño in boreal winter. J. Atmos. Sci., 69, 1706-1712, https:// doi.org/10.1175/JAS-D-12-023.1. 
Ding, Q., J. M. Wallace, D. S. Battisti, E. J. Steig, A. J. E. Gallant, H.-J. Kim, and L. Geng, 2014: Tropical forcing of the recent rapid Arctic warming in northeastern Canada and Greenland. Nature, 509, 209-212, https://doi.org/10.1038/nature13260.

Duchon, C. E., 1979: Lanczos filtering in one and two dimensions. J. Appl. Meteor., 18, 1016-1022, https://doi.org/10.1175/15200450(1979)018<1016:LFIOAT $>2.0$. CO;2.

Ebita, A., and Coauthors, 2011: The Japanese 55-Year Reanalysis "JRA-55": An interim report. SOLA, 7, 149-152, https:// doi.org/10.2151/sola.2011-038.

Feng, J., and J. Li, 2013: Contrasting impacts of two types of ENSO on the boreal spring Hadley circulation. J. Climate, 26, 4773 4789, https://doi.org/10.1175/JCLI-D-12-00298.1.

— L. Wang, W. Chen, S. K. Fong, and K. C. Leong, 2010: Different impacts of two types of Pacific Ocean warming on Southeast Asian rainfall during boreal winter. J. Geophys. Res., 115, D24122, https://doi.org/10.1029/2010JD014761.

_ W. When, and Y. Li, 2017: Asymmetry of the winter extratropical teleconnections in the Northern Hemisphere associated with two types of ENSO. Climate Dyn., 48, 2135-2151, https://doi.org/10.1007/s00382-016-3196-2.

Fraedrich, K., 1990: European grosswetter during the warm and cold extremes of the $\mathrm{El} \mathrm{Niño/Southern} \mathrm{Oscillation.} \mathrm{Int.}$ J. Climatol., 10, 21-31, https://doi.org/10.1002/joc.3370100104.

Francis, J. A., and E. Hunter, 2006: New insight into the disappearing Arctic sea ice. Eos, Trans. Amer. Geophys. Union, 87, 509-524, https://doi.org/10.1029/2006EO460001.

—_, and S. J. Vavrus, 2012: Evidence linking Arctic amplification to extreme weather in mid-latitudes. Geophys. Res. Lett., 39, L06801, https://doi.org/10.1029/2012GL051000.

— , and - 2015: Evidence for a wavier jet stream in response to rapid Arctic warming. Environ. Res. Lett., 10, 014005, https://doi.org/10.1088/1748-9326/10/1/014005.

Geng, X., W. Zhang, M. F. Stuecker, and F.-F. Jin, 2017: Strong sub-seasonal wintertime cooling over East Asia and Northern Europe associated with super El Niño events. Sci. Rep., 7, 3770, https://doi.org/10.1038/s41598-017-03977-2.

Ghatak, D., and J. Miller, 2013: Implications for Arctic amplification of changes in the strength of the water vapor feedback. J. Geophys. Res. Atmos., 118, 7569-7578, https://doi.org/ 10.1002/jgrd.50578.

Gong, T., S. B. Feldstein, and S. Lee, 2017: The role of downward infrared radiation in the recent Arctic winter warming trend. J. Climate, 30, 4937-4949, https://doi.org/10.1175/JCLI-D-160180.1.

Graversen, R. G., 2006: Do changes in the midlatitude circulation have any impact on the Arctic surface air temperature trend? J. Climate, 19, 5422-5438, https://doi.org/10.1175/JCLI3906.1.

Holland, M. M., and C. M. Bitz, 2003: Polar amplification of climate change in coupled models. Climate Dyn., 21, 221-232, https:// doi.org/10.1007/s00382-003-0332-6.

Honda, M., J. Inoue, and S. Yamane, 2009: Influence of low Arctic sea-ice minima on anomalously cold Eurasian winters. Geophys. Res. Lett., 36, L08707, https://doi.org/10.1029/ 2008 GL037079.

Hoskins, B. J., and D. J. Karoly, 1981: The steady linear response of a spherical atmosphere to thermal and orographic forcing. J. Atmos. Sci., 38, 1179-1196, https://doi.org/10.1175/15200469(1981)038<1179:TSLROA > 2.0.CO;2.

Hu, C., S. Yang, Q. Wu, Z. Li, J. Chen, K. Deng, T. Zhang, and C. Zhang, 2016a: Shifting El Niño inhibits summer Arctic warming and Arctic sea-ice melting over the Canada basin. Nat. Commun., 7, 11 721, https://doi.org/10.1038/ncomms11721.
— new pair of Niño indices for improving real-time ENSO monitoring. Climate Dyn., 47, 4031-4049, https://doi.org/ 10.1007/s00382-016-3059-x.

Inoue, J., M. E. Hori, and K. Takaya, 2012: The role of Barents Sea ice in the wintertime cyclone track and emergence of a warmArctic cold-Siberian anomaly. J. Climate, 25, 2561-2568, https://doi.org/10.1175/JCLI-D-11-00449.1.

Jin, F. F., 1997: An equatorial ocean recharge paradigm for ENSO. Part I: conceptual model. J. Atmos. Sci., 54, 811-829, https:// doi.org/10.1175/1520-0469(1997)054<0811:AEORPF >2.0.CO;2.

Johnson, N., and Y. Kosaka, 2016: The impact of eastern equatorial Pacific convection on the diversity of boreal winter El Niño teleconnection patterns. Climate Dyn., 47, 3737-3765, https:// doi.org/10.1007/s00382-016-3039-1.

Jung, O., M.-K. Sung, K. Sato, Y.-K. Lim, S.-J. Kim, E.-H. Baek, J.-H. Jeong, and B.-M. Kim, 2017: How does the SST variability over the western North Atlantic Ocean control Arctic warming over the Barents-Kara Seas? Environ. Res. Lett., 12, 034021, https://doi.org/10.1088/1748-9326/aa5f3b.

Kalnay, E., and Coauthors, 1996: The NCEP/NCAR 40-Year Reanalysis Project. Bull. Amer. Meteor. Soc., 77, 437-471, https:// doi.org/10.1175/1520-0477(1996)077<0437:TNYRP>2.0.CO;2.

Kao, H. Y., and J. Y. Yu, 2009: Contrasting eastern-Pacific and central-Pacific types of ENSO. J. Climate, 22, 615-632, https:// doi.org/10.1175/2008JCLI2309.1.

Khan, S. A., and Coauthors, 2014: Sustained mass loss of the northeast Greenland ice sheet triggered by regional warming. Nat. Climate Change, 4, 292-299, https://doi.org/10.1038/ nclimate2161.

Kim, H. M., P. Webster, and J. Curry, 2009: Impact of shifting patterns of Pacific Ocean warming on North Atlantic tropical cyclones. Science, 325, 77-80, https://doi.org/10.1126/ science. 1174062.

King, M. P., I. Herceg-Bulić, F. Kucharski, and N. Keenlyside, 2018a: Interannual tropical Pacific sea surface temperature anomalies teleconnection to Northern Hemisphere atmosphere in November. Climate Dyn., 50, 1881-1899, https:// doi.org/10.1007/s00382-017-3727-5.

, —, I. Bladé, J. García-Serrano, N. Keenlyside, F. Kucharski, C. Li, and S. Sobolowski, 2018b: Importance of late fall ENSO teleconnection in the Euro-Atlantic sector. Bull. Amer. Meteor. Soc., 99, 1337-1343, https://doi.org/ 10.1175/BAMS-D-17-0020.1.

Krishnamurti, T. N., R. Krishnamurti, S. Das, V. Kumar, A. Jayakumar, and A. Simon, 2015: A pathway connecting the monsoonal heating to the rapid Arctic ice melt. J. Atmos. Sci., 72, 5-34, https://doi.org/10.1175/JAS-D-14-0004.1.

Kug, J. S., F. F. Jin, and S. I. An, 2009: Two types of El Niño events: Cold tongue El Niño and warm pool El Niño. J. Climate, 22, 1499-1515, https://doi.org/10.1175/2008JCLI2624.1.

, J.-H. Jeong, Y.-S. Jang, B.-M. Kim, C. K. Folland, S.-K. Min, and S.-W. Son, 2015: Two distinct influences of Arctic warming on cold winters over North America and East Asia. Nat. Geosci., 8, 759-762, https://doi.org/10.1038/ngeo2517.

Larkin, N. K., and D. E. Harrison, 2005: On the definition of El Niño and associated seasonal average US weather anomalies. Geophys. Res. Lett., 32, L13705, https://doi.org/10.1029/ 2005GL022738.

Lee, S., 2012: Testing of the Tropically Excited Arctic Warming Mechanism (TEAM) with traditional El Niño and La Niña. J. Climate, 25, 4015-4022, https://doi.org/10.1175/JCLI-D-1200055.1. 
- 2014: A theory for polar amplification from a general circulation perspective. Asia-Pac. J. Atmos. Sci., 50, 31-43, https:// doi.org/10.1007/s13143-014-0024-7.

- S. Feldstein, D. Pollard, and T. White, 2011a: Do planetary wave dynamics contribute to equable climates? J. Climate, 24, 2391-2404, https://doi.org/10.1175/2011JCLI3825.1.

—, T. Gong, N. Johnson, S. B. Feldstein, and D. Pollard, 2011b: On the possible link between tropical convection and the Northern Hemisphere Arctic surface air temperature change between 1958 and 2001. J. Climate, 24, 4350-4367, https:// doi.org/10.1175/2011JCLI4003.1.

Lu, J., and M. Cai, 2010: Quantifying contributions to polar warming amplification in an idealized coupled general circulation model. Climate Dyn., 34, 669-687, https://doi.org/ 10.1007/s00382-009-0673-x.

McPhaden, M. J., T. Lee, and D. McClurg, 2011: El Niño and its relationship to changing background conditions in the tropical Pacific Ocean. Geophys. Res. Lett., 38, 175-188, https:// doi.org/10.1029/2011GL048275.

Moron, M., and I. Gouirand, 2003: Seasonal modulation of the ENSO relationship with sea level pressure anomalies over the North Atlantic in October-March 1873-1996. Int. J. Climatol., 23, 143-155, https://doi.org/10.1002/joc.868.

Neelin, J. D., D. S. Battisti, A. C. Hirst, F.-F. Jin, Y. Wakata, T. Yamagata, and S. E. Zebiak, 1998: ENSO theory. J. Geophys. Res., 103, 14 261-14 290, https://doi.org/10.1029/97JC03424.

Overland, J., and M. Wang, 2010: Large-scale atmospheric circulation changes are associated with the recent loss of Arctic sea ice. Tellus, 62A, 1-9, https://doi.org/10.1111/j.16000870.2009.00421.x.

— K. Kood, and M. Wang, 2011: Warm Arctic-cold continents: Climate impacts of the newly open Arctic sea. Polar Res., 30, 15 787, https://doi.org/10.3402/polar.v30i0.15787.

— weather to the changing Arctic. Nat. Climate Change, 6, 992 999, https://doi.org/10.1038/nclimate3121.

Papineau, J. M., 2001: Wintertime temperature anomalies in Alaska correlated with ENSO and PDO. Int. J. Climatol., 21, 1577-1592, https://doi.org/10.1002/joc.686.

Pithan, F., and T. Mauritsen, 2014: Arctic amplification dominated by temperature feedbacks in contemporary climate models. Nat. Geosci., 7, 181-184, https://doi.org/10.1038/ngeo2071.

Rayner, N. A., D. E. Parker, E. B. Horton, C. K. Folland, L. V. Alexander, D. P. Rowell, E. C. Kent, and A. Kaplan, 2003: Global analyses of sea surface temperature, sea ice, and night marine air temperature since the late nineteenth century. J. Geophys. Res., 108, 4407, https://doi.org/10.1029/ 2002JD002670.

Ren, H. L., and F. F. Jin, 2011: Niño indices for two types of ENSO. Geophys. Res. Lett., 38, L04704, https://doi.org/10.1029/ 2010GL046031.

Sassi, F. D., D. Kinnison, B. A. Boville, R. R. Garcia, and R. Roble, 2004: Effect of El Niño-Southern Oscillation on the dynami$\mathrm{cal}$, thermal, and chemical structure of the middle atmosphere. J. Geophys. Res., 109, D17108, https://doi.org/10.1029/ 2003JD004434.

Schopf, P. S., and M. J. Suarez, 1988: Vacillations in a coupled ocean-atmosphere model. J. Atmos. Sci., 45, 549-566, https://doi.org/10.1175/1520-0469(1988)045<0549: VIACOM $>2.0 . \mathrm{CO} ; 2$.

Screen, J. A., and I. Simmonds, 2010: The central role of diminishing sea ice in recent Arctic temperature amplification. Nature, 464, 1334-1337, https://doi.org/10.1038/nature09051.
— and _- 2013: Exploring links between Arctic amplification and mid-latitude weather. Geophys. Res. Lett., 40, 959-964, https://doi.org/10.1002/grl.50174.

Sellers, W. D., 1969: A global climate model based on the energy balance of the earth-atmosphere system. J. Appl. Meteor., 8, 392-400, https://doi.org/10.1175/1520-0450(1969)008<0392: AGCMBO $>2.0 . C O ; 2$.

Serreze, M. C., and J. A. Francis, 2006: The Arctic amplification debate. Climatic Change, 76, 241-264, https://doi.org/10.1007/ s10584-005-9017-y.

— , and R. G. Barry, 2011: Processes and impacts of Arctic amplification: A research synthesis. Global Planet. Change, 77, 85-96, https://doi.org/10.1016/j.gloplacha.2011.03.004.

— A. P. Barrett, and J. C. Stroeve, 2012: Recent changes in tropospheric water vapor over the Arctic as assessed from radiosondes and atmospheric reanalyses. J. Geophys. Res., 117, D10104, https://doi.org/10.1029/2011JD017421.

Shinoda, T., H, E. Hurlburt, and E. J. Metzger, 2011: Anomalous tropical ocean circulation associated with La Niña Modoki. J. Geophys. Res., 116, C12001, https://doi.org/10.1029/ 2011JC007304.

Stroeve, J. C., M. C. Serreze, M. M. Holland, J. E. Kay, J. Malanik, and A. P. Barrett, 2012: The Arctic's rapidly shrinking sea icecover: A research synthesis. Climatic Change, 110, 10051027, https://doi.org/10.1007/s10584-011-0101-1.

Stuecker, M. F., A. Timmermann, F.-F. Jin, Y. Chikamoto, W. Zhang, A. T. Wittenberg, E. Widiasih, and S. Zhao, 2017: Revisiting ENSO/Indian Ocean Dipole phase relationships. Geophys. Res. Lett., 44, 2481-2492, https://doi.org/10.1002/ 2016 GL072308.

— , and Coauthors, 2018: Polar amplification dominated by local forcing and feedbacks. Nat. Climate Change, 8, 1076-1081, https://doi.org/10.1038/s41558-018-0339-y.

Svendsen, L., N. Keenlyside, I. Bethke, Y. Gao, and N.-E. Omrani, 2018: Pacific contribution to the early twentieth-century warming in the Arctic. Nat. Climate Change, 8, 793-797, https://doi.org/10.1038/s41558-018-0247-1.

Tang, Q. H., X. Zhang, X. Yang, and J. A. Francis, 2013: Cold winter extremes in northern continents linked to Arctic sea ice loss. Environ. Res. Lett., 8, 014036, https://doi.org/10.1088/ 1748-9326/8/1/014036.

Tedeschi, R. G., I. F. A. Cavalcanti, and A. M. Grimm, 2013: Influences of two types of ENSO on South American precipitation. Int. J. Climatol., 33, 1382-1400, https://doi.org/10.1002/joc.3519.

Timmermann, A., and Coauthors, 2018: El Niño-Southern Oscillation complexity. Nature, 559, 535-545, https://doi.org/ 10.1038/s41586-018-0252-6.

Uppala, S. M., and Coauthors, 2005: The ERA-40 Re-Analysis. Quart. J. Roy. Meteor. Soc., 131, 2961, https://doi.org/10.1256/ qj.04.176.

Wallace, J. M., and D. S. Gutzler, 1981: Teleconnections in the geopotential height field during the Northern Hemisphere winter. Mon. Wea. Rev., 109, 784-812, https://doi.org/10.1175/ 1520-0493(1981)109<0784:TITGHF>2.0.CO;2.

, E. M. Rasmusson, T. P. Mitchell, V. E. Kousky, E. S. Sarachik, and H. von Storch, 1998: On the structure and evolution of ENSO related climate variability in the tropical Pacific: Lessons from TOGA. J. Geophys. Res., 103, $14241-$ 214259, https://doi.org/10.1029/97JC02905.

Weng, H., K. Ashok, S. K. Behera, S. A. Rao, and T. Yamagata, 2007: Impacts of recent El Niño Modoki on dry/wet conditions in the Pacific Rim during boreal summer. Climate Dyn., 29, 113-129, https://doi.org/10.1007/s00382-007-0234-0. 
Wilks, D. S., 2016: "The stippling shows statistically significant grid points": How research results are routinely overstated and overinterpreted, and what to do about it. Bull. Amer. Meteor. Soc., 97, 2263-2273, https://doi.org/10.1175/BAMS-D-1500267.1.

Wu, B., 2017: Winter atmospheric circulation anomaly associated with recent Arctic winter warm anomalies. J. Climate, 30, 8469-8479, https://doi.org/10.1175/JCLI-D-17-0175.1.

Wyrtki, K., 1975: El Niño-The dynamic response of the equatorial Pacific Ocean to atmospheric forcing. J. Phys. Oceanogr., 5, 572-584, https://doi.org/10.1175/1520-0485(1975)005<0572: ENTDRO $>2.0 . \mathrm{CO} ; 2$.

Yeh, S. W., J.-S. Kug, B. Dewitte, M.-H. Kwon, B. P. Kirtman, and F.-F. Jin, 2009: El Niño in a changing climate. Nature, $\mathbf{4 6 1}$, 511-514, https://doi.org/10.1038/nature08316.

$\mathrm{Yu}$, J. Y., and S. T. Kim, 2013: Identifying the types of major El Niño events since 1870. Int. J. Climatol., 33, 2105-2112, https:// doi.org/10.1002/joc.3575.

, Y. Zou, S. T. Kim, and T. Lee, 2012: The changing impact of El Niño on US winter temperature. Geophys. Res. Lett., 39, L15702, https://doi.org/10.1029/2012GL052483.

Zhang, W. J., J. Li, and F. F. Jin, 2009: Spatial and temporal features of ENSO meridional scales. Geophys. Res. Lett., 36, 401412, https://doi.org/10.1029/2009g1038672.
— , F.-F. Jin, J. Li, and H.-L. Ren, 2011: Contrasting impacts of two-type El Niño over the western North Pacific during boreal autumn. J. Meteor. Soc. Japan, 89, 563-569, https://doi.org/ 10.2151/jmsj.2011-510.

— , F. Jin, J. Zhao, L. Qi, and H. Ren, 2013: The possible influence of a non-conventional El Niño on the severe autumn drought of 2009 in southwest China. J. Climate, 26, 8392-8405, https://doi.org/10.1175/JCLI-D-12-00851.1.

— , F. F. Jin, and A. Turner, 2014: Increasing autumn drought over southern China associated with ENSO regime shift. Geophys. Res. Lett., 41, 4020-4026, https://doi.org/10.1002/ 2014GL060130.

- - L. Wang, B. Xiang, L. Qi, and J. He, 2015: Impacts of two types of La Niña on the NAO during boreal winter. Climate Dyn., 44, 1351-1366, https://doi.org/10.1007/s00382014-2155-z.

, and Coauthors, 2016: Unraveling El Niño's impact on the East Asian Monsoon and Yangtze River summer flooding. Geophys. Res. Lett., 43, 11375-11382, https://doi.org/10.1002/ 2016GL071190.

Z. Wang, M. F. Stuecker, A. G. Turner, F.-F. Jin, and X. Geng, 2019: Impact of ENSO longitudinal position on teleconnections to the NAO. Climate Dyn., 52, 257-274, https:// doi.org/10.1007/s00382-018-4135-1. 